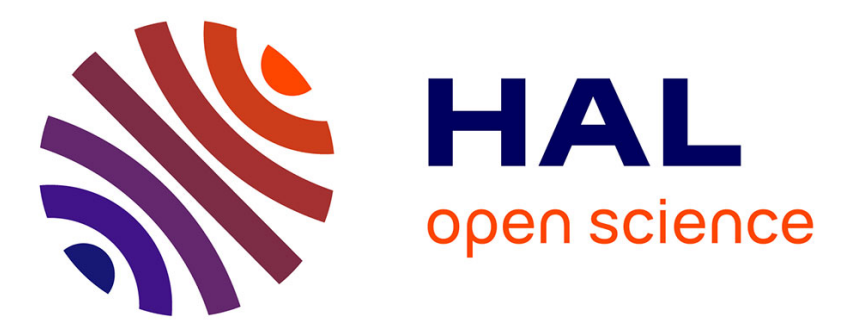

\title{
Identification of essential amino acid residues in a sterol 8,7-isomerase from Zea mays reveals functional homology and diversity with the isomerases of animal and fungi origin
}

\author{
Alain Rahier, Sylvain Pierre, Geneviève Riveill, Francis Karst
}

\section{To cite this version:}

Alain Rahier, Sylvain Pierre, Geneviève Riveill, Francis Karst. Identification of essential amino acid residues in a sterol 8,7-isomerase from Zea mays reveals functional homology and diversity with the isomerases of animal and fungi origin. Biochemical Journal, 2008, 414 (2), pp.247-259. 10.1042/BJ20080292 . hal-00478970

\section{HAL Id: hal-00478970 https://hal.science/hal-00478970}

Submitted on 30 Apr 2010

HAL is a multi-disciplinary open access archive for the deposit and dissemination of scientific research documents, whether they are published or not. The documents may come from teaching and research institutions in France or abroad, or from public or private research centers.
L'archive ouverte pluridisciplinaire $\mathbf{H A L}$, est destinée au dépôt et à la diffusion de documents scientifiques de niveau recherche, publiés ou non, émanant des établissements d'enseignement et de recherche français ou étrangers, des laboratoires publics ou privés. 
Identification of essential amino acid residues in a sterol 8,7-isomerase from Zea mays reveals functional homology and diversity with the isomerases of animal and fungi origin.

Alain RAHIER*, Sylvain PIERRE*, Geneviève RIVEILL ${ }^{+}$and Francis KARST ${ }^{+}$.

From the *Institut de Biologie Moléculaire des Plantes, CNRS, UPR2357, 28 rue Goethe, 67083 Strasbourg cedex, France and +UMR 1131, INRA, Université Louis Pasteur, F-68000 Colmar, France.

Short Title: Plant sterol 8,7-isomerase essential amino-acids.

Address correspondance to : Alain Rahier, Institut de Biologie Moléculaire des Plantes, 28 rue Goethe, 67083 Strasbourg cedex, France. Tel. 33390241861 , Fax 33390242002

E-mail: alain.rahier@ibmp-ulp.u-strasbg.fr

Key words : sterol 8,7-isomerase, mutagenesis, inhibition, plant sterol, 


\section{SYNOPSIS}

A putative sterol 8,7-isomerase (8,7SI) from Zea mays termed Zm8,7SI has been isolated from an EST library and subcloned in the yeast erg2 mutant lacking 8,7SI activity. $Z m 8$,7SI restored endogenous ergosterol synthesis. An in vitro enzymatic assay in the corresponding yeast microsomal extract indicated that the preferred $\Delta^{8}$-sterol substrate possesses a single $\mathrm{C} 4 \alpha$ methyl group, in contrast to 8 ,7SIs from animals and fungi, thus reflecting the diversity in the structure of their active site in relation to the distinct sterol biosynthetic pathways. In accordance with the proposed catalytic mechanism, a series of lipophilic ammonium ion containing derivatives possessing a variety of structures and biological properties, potently inhibited the Zm8,7SI in vitro. To evaluate the importance of a series of conserved acidic and tryptophan residues which could be involved in Zm8,7SI catalytical mechanism, 20 mutants of $Z m 8,7-S I$ were constructed as well as a number of corresponding mutants of the S.cerevisiae 8,7-SI. The mutated isomerases were assayed in vivo by sterol analysis and quantification of $\Delta^{5,7}$-sterols and directly in vitro by examination of the activities of the recombinant $\mathrm{Zm8}$,7-SI mutants. These studies have identified $\mathrm{His}^{74}, \mathrm{Glu}^{78}$, $\mathrm{Asp}^{107}, \mathrm{Glu}^{121}, \operatorname{Trp}^{66}$ and $\operatorname{Trp}^{193}$ that are required for $\mathrm{Zm8,7SI}$ activity and show that binding of the enzyme-substrate complex is impaired in mutant T124I. They underline the functional homology between the plant and animal 8 ,7SIs on one hand, in contrast to the yeast $8,7 \mathrm{SI}$ on the other hand, in accord with their molecular diversity and distinct mechanisms. 


\section{INTRODUCTION}

Sterols are essential components of all eukaryotic cell membranes. The structural differences between sterols of animal, plant and fungi are linked to the biosynthetic pathways that differ significantly downstream squalene epoxide [1-3]. Nevertheless, these pathways retain several enzymatic steps in common, as for example those which together are necessary for the migration of the initial unsaturation in the $\mathrm{B}$ ring to the $\Delta^{5}$ position in the functional sterols. This includes isomerization of the $\mathrm{C} 8$ double bond to the $\mathrm{C} 7$ position catalyzed by the sterol 8,7-isomerase (8,7SI) (Figure 1). The sterol 8,7-isomerization is triggered by an $\alpha$ protonation of the $\Delta^{8}$-double bond from an appropriately positioned general acid residue giving a C8 carbocationic high energy intermediate (HEI). It follows elimination of a proton at C7 accepted by a general base residue (Figure 1) [4]. Loss of the $7 \beta-\mathrm{H}$ occurs in animals $[5,6]$ and plants [7], while in fungi the enzyme proceeds with elimination of the $7 \alpha-\mathrm{H}[7,8]$ (Figure 1).

$8,7 \mathrm{SI}$ is one of the sterol biosynthesis enzymes that deserves special attention. In yeast, sterol 8,7-isomerase is a high regulated step of sterol biogenesis [9]. It is the primary target for a variety of compounds widely used in agriculture and medecine [2, 10-14]. Azadecalines [15], morpholine and piperidine fungicides [12] inhibit the plant and yeast enzymes by mimicking the structure of the carbocationic HEI. The animal 8,7SI is inhibited by a variety of structurally distinct pharmacological compounds including receptor $\sigma$-ligand SR31747A [16], trifluoperazine [11,17] and tamoxifen [11]. In addition, the $\sigma$-ligands, haloperidol, ifenprodil and verapamil were shown to inhibibit the production of ergosterol in wild-type $S$. cerevisiae [11] and in the erg2 mutant complemented with A.thaliana 8,7SI cDNA [18].

cDNAs of sterol 8,7-isomerase genes from fungi, animals and plants have been isolated and in some cases functionally characterized by complementation in the yeast erg2 mutant deficient in 8,7 SI $[19,16,18]$. The mammalian 8,7 SI was shown to correspond to the EBP (emopamil binding protein), a high affinity receptor for the phenylalkylamine calciumantagonist emopamil and other antiischaemic drugs, previously isolated [20]. A number of syndromes caused by EBP gene mutations, such as X-linked dominant Conradi-Hünermann syndrome and CHILD (congenital hemidysplasia with ichthyosiform erythroderma and limb defect), or the "tattered" mouse phenotype, were characterized by abnormally increased levels of cholest-8(9)-en-3 $\beta$-ol due to inactivation of 8,7SI. [21-23]. Human 8,7SI (EBP) and the yeast isoenzyme (Erg2p) are structurally unrelated and differ particularly in the substrate 
specificity [5,7]. Alanine scanning mutagenesis was used to identify residues of human EBP required for in vivo sterol 8,7-isomerization [24]. It is noteworthy that a mammalian protein that is structurally related to the yeast Erg2p has been described as an $\sigma_{1}$ receptor but it exhibits no SI activity upon expression in yeast [25].

In plants, most of reports on enzymes involved in the kinetic control of the post squalene sterol pathway have been described in Zea mays [2]. Moreover, Zea mays has been widely used as a monocot model to assay both in vivo and in vitro a variety of fungicides and herbicides inhibiting plant sterol biosynthesis [10]. A plant 8,7SI cDNA has also been isolated by functional complementation of the corresponding yeast sterol mutant (erg2) by an Arabidopsis cDNA library and characterized by exposure to o-ligands [18]. The plant 8,7SI shows an homology with the animal enzyme and is not related to the yeast enzyme. The importance of a functional 8,7SI for normal plant growth and development has been shown using the Arabidopsis hydra mutants, deficient in 8,7SI [26].

In plants, little attention has been directed towards the in vitro enzymological characterization of $8,7 \mathrm{SI}$, including features required for specificity of sterol substrate. This is particularly due to the difficulties in obtaining the substrates and sufficient amounts of microsomal protein required, as the $\mathrm{V}_{\max }$ of the enzymes of postsqualene phytosterol synthesis are low [2]. In addition, the integral membrane-bound nature of the 8,7SI renders a structural characterization through crystallization and/or NMR challenging.

Site-directed mutational analysis of plant and yeast 8,7SIs has not been performed so far to establish the importance of select amino-acids in the proteins and to identify aminoacids essential for catalysis.

In this study, we report the cloning and in vivo functional expression in yeast, of a 8,7SI cDNA from Zea mays, and the first in vitro enzymological characterization and inhibition analysis of a plant recombinant 8,7SI. Moreover, to provide a framework for future structural studies, we report here the first site directed mutagenesis analysis of plant and yeast 8,7 SIs. We mutated a number of conserved acidic residues, or putative cation stabilizing tryptophane residues, looking for amino acid residues that are essential for catalytic activity. The mutated isomerases were assayed both in vivo by sterol analysis and quantification of $\Delta^{5,7}$-sterols, and directly in vitro by examinating the activities of the recombinant mutated $\mathrm{Zm} 8$,7SI in the corresponding yeast microsomes extracts. It allowed particularly the identification of a number of amino acid residues essential for the plant 8,7SI activity. Taken 
together, the data revealed functional homology and diversity with the isomerases of animal and fungi.

\section{EXPERIMENTAL.}

\section{Materials}

Tamoxifen (16) (Figure 2) and Trifluoperazine (15) were purchased from Sigma. N-benzyl$4 \alpha, 10$-dimethyl-8-aza-trans-decal-3 $\beta$-ol (17), N-[(1,5,9)-trimethyldecyl]-4 $\alpha, 10$-dimethyl-8aza-trans-decal-3 $\beta$-ol (18) and N-benzamido-4 $\alpha, 10$-dimethyl-8-aza-trans-decal-3 $\beta$-ol (19) were synthesized as previously described [15,27]. AY9944 (13) was a generous gift of Dr. Dvornik (Ayerst Research Lab. Montreal, Canada). We thank the BASF Agrochemical Station (Limburgerhof, Germany) for providing Tridemorph (11) and Fenpropimorph (12). SR31747 (14) was provided by Dr Loison, (Sanofi-Aventis Recherche-Developpement, Labège, France).

\section{Strains and plasmids}

The sterol 8,7-isomerase deficient strain, WA10-3-1D (Mat a, erg2-4 ::LEU2, ura3-52, leu23, leu2-112, his7-2, ade5) used in this study has been previously described [19]. The strain was grown aerobically at $30^{\circ} \mathrm{C}$ on solid or liquid minimal medium (yeast nitrogen base (DIFCO) $0.67 \%(\mathrm{w} / \mathrm{v}), 2 \%(\mathrm{w} / \mathrm{v})$ glucose) containing suitable supplements $(50 \mathrm{mg} / \mathrm{liter}$ each) and casamino acids (1g/liter), or complete medium (YPD 1\% (w/v) yeast extract, 2\% $(\mathrm{w} / \mathrm{v})$ peptone, $2 \%(\mathrm{w} / \mathrm{v})$ glucose). The yeast strain $\Delta$ erg2pEMR1235 containing the murine 8,7SI was provided by Dr Loison. The pVT102U [28] S.cerevisiae shuttle vector optimized for expressing recombinant proteins in yeast was used for cloning, sequencing and transformation of the erg2 strain. This plasmid contains an E.coli origin of replication, a yeast $2 \mu$ origin of replication, an E.coli ampicillin resistance gene and the yeast URA3 gene. It contains also an expression cassette including the alcohol dehydrogenase $(A D H 1)$ promotor and terminator.

\section{Molecular Cloning}




\section{Zea mays 8,7SI}

A BLAST search with the A.thaliana 8,7SI and the emopamil binding protein from H.sapiens revealed significant sequence similarities with the hypothetical protein of a Zea mays EST clone (GenBank accession no BG840208) which was obtained from the Schnable laboratory of the Iowa State University of Science and Technology (USA). Sequencing of this EST clone revealed that it contained a complete ORF which was PCR amplified with the primer pair P1 (Table 1) containing an XbaI site, and the reverse primer P2 containing an Xhol site. This 666-bp cDNA termed Zm8,7SI (AY533175) was cloned between the XbaI and XhoI sites of the pVT102U shuttle vector and placed under the control of the constitutive alcohol dehydrogenase promoter to generate the plasmid pVT-Zm8,7SI. Both strands of the amplified cDNA were sequenced to ensure sequence fidelity.

\section{Zea mays FLAG 8,7SI}

In order to check the expression and accumulation of wild-type and mutated Z.mays 8,7SIs proteins in yeast microsomes, an N-terminal FLAG epitope (MDYKDDDDK) was fused to the 8,7SI protein. For this purpose a DNA molecule containing at 5'-end the corresponding nucleotide sequence was synthesized by PCR using the following forward primer : P3 containing an XbaI site and the reverse primer P2 using the Zm8,7SI cDNA as a template. The ZmFLAG8,7SI was further cloned between the XbaI and XhoI sites of the pVT102U vector to generate pVT-ZmFLAG8,7SI.

\section{Site-directed mutagenesis}

Site-directed mutagenesis was performed using the "Quickchange Site-Directed Mutagenesis Kit" (Stratagene) according to the manufacturer's instructions. pVT- Zm8,7SI or pVTZmFLAG8,7SI were used as a template and the synthetic oligonucleotide primers listed in Table 1. Putative, positive clones were picked, plasmids isolated and sequenced.

\section{Transformations}

S.cerevisiae transformations were performed using the lithium acetate procedure as previously described [29]. The transformed erg2 yeast strain was plated on minimal YNB medium containing adenine and histidine, $50 \mathrm{mg} \mathrm{mL}^{-1}$ each. Cells were grown aerobically at $30^{\circ} \mathrm{C}$. 


\section{Sterol Analysis}

Lyophilized yeast cells (10 to 30mg) were sonicated in the presence of methanol/KOH $(6 \%$, $\mathrm{w}: \mathrm{v}, 2 \mathrm{ml}$ ) for $10 \mathrm{~min}$ and heated in the same medium at $70^{\circ} \mathrm{C}$ under reflux conditions for $2 \mathrm{~h}$. The mixture was diluted with 1 volume of water and total sterols were extracted three times with 1 volume of hexane. The extract was dried on $\mathrm{Na}_{2} \mathrm{SO}_{4}$ and evaporated to dryness. Sterols were analyzed by gas chromatography. GC analysis was carried out with a Varian GC model 8300 equipped with a flame ionization detector at $300^{\circ} \mathrm{C}$, column injector at $250^{\circ} \mathrm{C}$ and a fused capillary column (WCOT $: 30 \mathrm{~m} \times 0.25 \mathrm{~mm}$ i.d.) coated with $\mathrm{DB} 1\left(\mathrm{H}_{2}\right.$ flow rate of $2 \mathrm{~mL} / \mathrm{min}$ ). The temperature program used included a $30^{\circ} \mathrm{C} / \mathrm{min}$ increase from 60 to $240^{\circ} \mathrm{C}$ and followed by a $2^{\circ} \mathrm{C} / \mathrm{min}$ increase from 240 to $280^{\circ} \mathrm{C}$. Relative retention times $\left(t_{R}\right)$ are given with respect to cholesterol $\left(t_{R}=1\right)$. Identification of individual sterols was performed using a GC-MS spectrometer (Agilent 5973N) equipped with an "on column" injector and a capillary column (30m x 0.25 i.d.) coated with DB5. Sterols were unequivocally identified by retention times and an electron impact spectrum identical to that of authentic standards [30].

\section{Substrates}

Melting points are uncorrected. Proton magnetic resonance was monitored in a $\left[{ }^{2} \mathrm{H}\right]-$ chloroform solution with a Brucker 400 or $500 \mathrm{Mhz}$ spectrometer. Chemical shifts (d) (ppm) were determined relative to tetramethylsilane. Coupling constants $(\mathrm{J})$ were in Hertz.

$\Delta^{8}$-Sitostenol (1) (24(R)-24-ethyl-5 $\alpha$-stigmasta-8-en-3 $\beta$-ol(1) was extracted from bramble (Rubus fruticosus) suspension cultures treated with AY 9944 as previously described [31]. GC purity $>98 \%\left(t_{R}=1.233, \mathrm{DB} 1\right), \mathrm{MS} m / z$ (rel.int.) $\mathrm{M}^{+}=414(100), 399(42), 381(8)$, 315(13), 273(20), 255(19), 229(20), 213(20). ${ }^{1} \mathrm{H}-\mathrm{NMR}\left(\mathrm{CDCl}_{3}\right)$ (acetate derivative): $\delta$ : $0 ; 605(3 \mathrm{H}, \mathrm{s}, \mathrm{H} 18), 0,812(3 \mathrm{H}, \mathrm{d}, \mathrm{J}=6.6, \mathrm{H} 26), 0.835(3 \mathrm{H}, \mathrm{d}, \mathrm{J}=6.6, \mathrm{H} 27), 0.843(3 \mathrm{H}, \mathrm{t}, \mathrm{J}=6, \mathrm{H} 29)$,

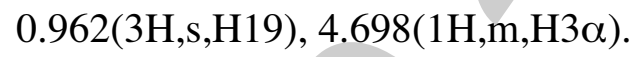

Zymosterol (2) was isolated from the yeast strain erg6, erg2 and crystallized from methanol: mp 107-109 ${ }^{\circ} \mathrm{C}$. GC purity $>98 \%\left(\mathrm{t}_{\mathrm{R}}=1.057, \mathrm{DB} 1\right) \mathrm{MS} \mathrm{m} / \mathrm{z}$ (rel.int.) $\mathrm{M}^{+}=384(88), 369(100)$, 351(25), 271(39), 229(40). ${ }^{1} \mathrm{H}-\mathrm{NMR}\left(\mathrm{CDCl}_{3}\right): \delta: 0.610(3 \mathrm{H}, \mathrm{s}, \mathrm{H} 18), 0.944(3 \mathrm{H}, \mathrm{d}, \mathrm{J}=5.2, \mathrm{H} 21)$, $0.950(3 \mathrm{H}, \mathrm{s}, \mathrm{H} 19), \quad 1.601(3 \mathrm{H}, \mathrm{s}, \mathrm{H} 27), \quad 1.681(3 \mathrm{H}, \mathrm{d}, \mathrm{J}=0.8, \mathrm{H} 26), \quad 3.614(1 \mathrm{H}, \mathrm{m}, \mathrm{H} 3 \alpha)$, $5.093(1 \mathrm{H}, \mathrm{tt}, \mathrm{J}=7.1, \mathrm{~J}=1.4, \mathrm{H} 24)$.

4a-Methyl-fecosterol (3), 4,4-dimethyl-zymosterol (4) and 4,4-dimethyl-fecosterol (5) were isolated from the wild type yeast strain FL530 grown in the presence of 6-Amino-2-npentylthiobenzothiazole (APB) or from the mutant erg-25-25c, as previously described [32]. 
$4 \alpha$-Methyl-fecosterol (3) : GC purity $>98 \%\left(\mathrm{t}_{\mathrm{R}}=1.198, \mathrm{DB} 1 ; \mathrm{t}_{\mathrm{R}}=1.175, \mathrm{DB} 5\right), \mathrm{MS}, \mathrm{m} / z$ (rel. int.) $\mathrm{M}^{+}=412(100)$, 397(68), 379(27), 285(46), 227(31).

4,4-dimethyl-zymosterol (4): GC purity $>98 \%\left(\mathrm{t}_{\mathrm{R}}=1.241, \mathrm{DB} 1 ; \mathrm{t}_{\mathrm{R}}=1.210, \mathrm{DB} 5\right), \mathrm{MS}, \mathrm{m} / \mathrm{z}$ (rel. int.) $\mathrm{M}^{+}=$412(100), 397(70), 379(39), 299(23), 259(35), 241(46).

4,4-dimethyl-fecosterol (5): $\mathrm{GC}$ purity $>98 \%\left(\mathrm{t}_{\mathrm{R}}=1.313, \mathrm{DB} 1 ; \mathrm{t}_{\mathrm{R}}=1.267, \mathrm{DB} 5\right), \mathrm{MS}, \mathrm{m} / \mathrm{z}$ (rel. int.) $\mathrm{M}^{+}=426(100)$, 411(45), 393(26), 342(3), 327(8), 299(26), 259(21), 241(22).

Obtusifoliol (6) was synthezised as previously described [33]. $\mathrm{mp} 139-141^{\circ} \mathrm{C}$ from methanol, GC purity $>98 \%\left(\mathrm{t}_{\mathrm{R}}=1.165, \mathrm{DB} 5\right), \mathrm{MS}, m / z$ (rel. int.) $\mathrm{M}^{+}=426(30), 411(100), 393(15)$, 327(13), 259(8), 245(25), 215(10).

Cholest-8(14)-en-3 $\beta$-ol (7) was synthezised as previously described [34]. $\mathrm{mp}=129-131^{\circ} \mathrm{C}$ from methanol, GC purity $>98 \%\left(\mathrm{t}_{\mathrm{R}}=1.010, \mathrm{DB} 1\right), \mathrm{MS}, \mathrm{m} / z$ (rel. int.) $\mathrm{M}^{+}=386(100)$, 371(33), 353(12), 273(13), 255(10). ${ }^{1} \mathrm{H}-\mathrm{NMR}\left(\mathrm{CDCl}_{3}\right): \delta: 0.829(3 \mathrm{H}, \mathrm{s}, \mathrm{H} 18)$, $0.872(3 \mathrm{H}, \mathrm{d}, \mathrm{J}=6.6, \mathrm{H} 26$ or $\mathrm{H} 27), 0.875(3 \mathrm{H}, \mathrm{d}, \mathrm{J}=6.6, \mathrm{H} 26$ or $\mathrm{H} 27), 0.906(3 \mathrm{H}, \mathrm{s}, \mathrm{H} 19)$, $0.916(3 \mathrm{H}, \mathrm{d}, \mathrm{J}=6.4, \mathrm{H} 21), 3$;803(1H,tt,J=11, J=4.7,H3 $\alpha), 5,159(1 \mathrm{H}, \mathrm{s}, \omega=6.5, \mathrm{H} 15)$.

\section{Standard assay for recombinant maize sterol 8,7-isomerase in yeast microsomes.}

Yeast microsomes were prepared as previously described [32]. Microsomes (0.4 mL, $1.0 \mathrm{mg}$ of protein) were incubated in the presence of exogenous $\Delta^{8}$-sitostenol (1) $(20-150 \mu \mathrm{M})$ emulsified with Tween 80 (final concentration $1.5 \mathrm{~g} /$ liter). Incubations were continued aerobically at $30^{\circ} \mathrm{C}$ with gentle stirring for $90 \mathrm{~min}$. During this period the progression of the reaction was linear. The reaction was stopped by adding $1 \mathrm{ml}$ of $6 \%$ (w/v) $\mathrm{KOH}$-ethanol. Sterols were extracted three times with a total volume of $15 \mathrm{ml}$ of $n$-hexane, and after drying with $\mathrm{Na}_{2} \mathrm{SO}_{4}$, the extract was concentrated to dryness. The extracts were further analyzed by thin-layer chromatography on silica gel, using dichloromethane as the eluant (developed twice). The 4-desmethylsterols $\left(R_{f}=0.30\right)$ were separated from $4 \alpha$-methylsterols $\left(R_{f}=0.40\right)$ and from 4,4-dimethylsterols $\left(\mathrm{R}_{\mathrm{f}}=0.45\right)$. After elution from the silica gel, an aliquot of the 4desmethyl fraction was analyzed by gas-liquid chromatography. The residual substrate $\Delta^{8}$ sitostenol $(\mathbf{1})\left(t_{R}=1.233\right)$ and the product formed, $\Delta^{7}$-sitostenol $(8)\left(t_{R}=1.265\right)$ were readily separated from each other and from the bulk of endogenous 4-desmethylsterols, including ergosterol $\left(t_{R}=1.083\right)$ (Figure A Sup. Mat.). The $\Delta 7$ metabolite $(8)$ produced by the reaction was unequivocally identifed by its retention time on GC and by an electron impact mass spectrum identical to that of an authentic standard (Table 2). The conversion ratio was calculated from the areas of the peaks of $\Delta^{7}$-sitostenol $(\mathbf{8})$ and $\Delta^{8}$-sitostenol (1) and corrected 
with the values obtained in the corresponding assay using boiled microsomes. The rate of substrate isomerization was calculated from the conversion ratio of (1) into (8), and the concentration of substrate used in the reaction. Apparent maximum velocity $\left(\mathrm{V}_{\max }\right)$ and $\mathrm{K}_{\mathrm{m}}$ values were determined by fitting the data to the Michaelis-Menten equation using the nonlinear regression program DNRP-EASY derived by Duggleby and Leonard from DNRP53 [35].

In the case of inhibition assays, microsomes were incubated for 90 min at $30^{\circ} \mathrm{C}$ in the presence of $(\mathbf{1})(100 \mu \mathrm{M})$ and a range of concentration of inhibitors $(0.01-50 \mu \mathrm{M})$ from which the dose-response curves were obtained allowing the corresponding $I_{50}$ values to be determined. The deviation between two determinations did not exceed $15 \%$.

Previous studies revealed that inhibition of postsqualene enzymes of sterol biosynthesis by ammonium analogues of carbocationic high energy intermediates follows a non-competitive kinetic inhibition pattern as a consequence of a slow rate of dissociation of the enzyme-inhibitor complex [10,36]. Assuming that inhibition of 8,7 SI by tertiary ammonium derivatives follows such a non-competitive kinetic inhibition pattern, the $I_{50}$ values measured should be independent of the substrate concentration as well as of the $\Delta^{8}$ sterol substrate used.

S.cerevisiae 8,7SI and murine 8,7SI were assayed as previously described in respectively [16] and [17].

Membrane proteins were quantified using the Bio-Rad protein assay according to Bradford [37].

Western blots of microsomes $(40 \mu \mathrm{g}$ protein) or of $100000 \mathrm{~g}$ supernatants from ZmFLAG8,7SIs transformed yeast were achieved after separation of proteins on SDS-14\% $(\mathrm{w} / \mathrm{v})$ polyacrylamide gel. After electrophoretic transfert to a polyvinylidene difluoride (PVDF) Immobilon P membrane (Millipore), ZmFLAG8,7SI was immunoblotted with affinity purified murine monoclonal ANTI-FLAG M2 antibodies from Sigma (1/6000 dilution) according to the manufacturer instructions. Goat anti-mouse IgG-alkaline phosphatase conjugate (Bio-Rad) was used as secondary antibody (1/10000 dilution). The membrane was then treated with the chemiluminescent AP substrate and the blot was further used to expose an instant film for detection.

\section{Incubation of substrate analogs and identification of enzyme-generated products.}


The apparent $\mathrm{K}_{\mathrm{m}}$ and $\mathrm{V}_{\max }$ of analogs (1), (2) and (3) were determined by incubating them for 60-90 min at $30^{\circ} \mathrm{C}$ under standard assay conditions in a yeast microsomal preparation of recombinant $Z m 8$,7SI. The concentration of substrate was 40-150 $\mu \mathrm{M}$. In the case of (3) and (6), the $4 \alpha$-methylsterol fraction was analyzed by GC-MS. In the case of $\Delta^{8}$-sterols (4) and (5), the 4,4-dimethylsterols fraction was analyzed by GC-MS. The 8,7SI products were unequivocally identified by their retention time and an electron impact spectrum identical to that of authentic standards (Table 2). The extracts of incubations of $\Delta^{8}$-sterols (4), (5), (6), and (7) and of the corresponding controls performed with inactivated microsomes revealed the absence of isomerization product and complete recovery of these compounds which was confirmed by ion monitoring that corresponded to the mass of the substrate and expected $\Delta^{7}$ sterol product.

\section{Sequence alignment.}

Multiple amino-acid sequences were aligned with Clustal W algorithm.

\section{RESULTS.}

\section{Characterization of sterol-8,7-isomerase from Zea mays.}

Cloning of sterol-8,7-isomerase in Zea mays and sequence analysis.

We identified a maize EST clone encoding a protein presenting $54 \%$ identity with the previously identified 8,7SI from A.thaliana [18] and 36\%identity with the Homo sapiens EBP protein [38]. However, the predicted protein showed only $15 \%$ identity with the ERG2 protein from S. cerevisiae [19] (Figure 3). Analysis of the Zm8,7SI protein sequence indicated the presence of four transmembrane spanning domains similar in order, spacing and length to those found in murine 8,7SI [16] but clearly distinct to the three-hydrophobic domain model observed for the yeast $8,7 \mathrm{SI}$. In addition, $\mathrm{Zm8}$,7SI possesses a C-terminal ER retrieval signal KKXK.

Zm8,7SI can complement the erg2 strain deficient in 8,7SI.

To further characterize the function of the cloned full-length Zm8,7SI, we performed a yeast complementation assay in the ERG2-deficient strain lacking the 8,7-sterol isomerase activity necessary to synthesize ergosterol. The Zm8,7SI ORF was cloned into the pVT102U shuttle vector under the control of the constitutive alcohol dehydrogenase promotor. Several pVT transformants were picked from the selection plate and propagated in liquid media. After 
sterol extraction, the sterol profiles were analyzed by GC and GC-MS. The strains erg2-pVTZm8,7SI and erg2-pVT-ZmFLAG8,7SI accumulated ergosterol (44 -57\%) as the major sterol, several $\Delta^{7}$-sterols $(8-10 \%)$ and residual amounts (26-37\%) of $\Delta^{8}$-sterols (Table 3). In comparison, the erg2-pVT-VOID (without insert) control strain produced exclusively $\Delta^{8}$ sterols (Table 3). These results demonstrate that Zm8,7SI and ZmFLAG8,7SI can efficiently complement the erg2 strain and restore endogenous ergosterol synthesis.

\section{Zm8,7SI has sterol 8,7-isomerase activity in vitro.}

An enzymatic assay was performed to test whether the recombinant putative Zm8,7SI protein in the transformed erg 2 strain indeed possesses sterol 8,7-isomerase activity. Purification of plant membrane proteins for functional analysis after expression in yeast is still a relatively unexplored field with little documentation in the literature. Additionally, in the case of an enzyme which is membrane-bound, interactions with other components of the membrane may be necessary for optimum enzymatic activity. Thus, 8,7SI activity was assayed in the microsomes extracts prepared from erg2-pVT-VOID, erg2-pVT-Zm8,7SI and erg2-pVT-ZmFLAG8,7SI by using the standard assay conditions for recombinant 8,7SI described under "Experimental procedure". The results from these studies revealed that microsomes extracts obtained from erg2-pVT-Zm8,7SI and erg2-pVT-ZmFLAG8,7SI were able to isomerize the 8,7 -SI substrate, $\Delta^{8}$-sitostenol $(\mathbf{1})$, to produce a single $\Delta^{7}$-sterol metabolite, $\Delta^{7}$-sitostenol (8) which was unequivocally identified by GC-MS analysis (Table 2, Figure A supplementary material). 8,7SI activity was undetectable in reactions with microsomal extract of erg2-pVT-VOID. The observed catalytical competence of Zm8,7SI revealed that it indeed encodes a membrane-bound maize 8,7-SI.

\section{Substrate specificity of $\mathrm{Zm8}$,7SI.}

A series of $\Delta^{8}$-sterols with distinct nucleus or side-chain structures were assayed with the recombinant $Z m 8$,7SI (Table 4). The apparent kinetic parameters of Zm8,7SI with substrates $\Delta^{8}$-sitostenol (1), zymosterol (2) and $4 \alpha$-methylfecosterol (3) were determined by varying their concentration under our standard assay conditions. The velocity/substrate concentration curves obey simple Michaelis-Menten kinetics with respect to (1), (2) and (3) (Figure B supplementary material) and the obtained kinetics data are summarized in Table 4. The data indicate that $\Delta^{8}$-sterol (1), and (2) without methyl group at C4 $\beta$ and $\mathrm{C} 14 \alpha$ were productive substrates and that (3) possessing a single $\mathrm{C} 4 \alpha$-methyl substituent had the highest 
apparent relative specificity constant $\left(\mathrm{V}_{\max } / \mathrm{K}_{\mathrm{m}}\right)$ in the series and thus appeared to be the preferred substrate of the isomerase. In contrast the presence of an additional C4 $\beta$-methyl group in substrates (4) and (5) abolishes activity as did the addition of a C14-methyl group as in substrate (6). While the enzyme can catalyze the isomerization of various $\Delta^{8}$-sterols, the $\Delta^{8(14)}$-monoene analog (7) is not isomerized indicating the strong regioselectivity of the isomerase for the substrate double bond localisation. Finally, the terminal part of the side chain was not essential to activity. As shown in Table 4, absence of substituent at C24 (structure 2) or addition of one or two carbons atom substituent at C24, (3) and (1), were not structural deterrents for the 8,7 SI activity.

\section{Inhibition of 8,7SI by lipophilic tertiary ammonium derivatives.}

We first synthesized in our laboratory a series of rationally designed carbocationic HEI analogues, including compounds (17) and (18), possessing a nitrogen atom with a steady positive charge in place of carbenium-C, which could simulate the C8-HEI [10,15]. With this mechanism in mind, inhibition of the recombinant $Z m 8$,7SI activity by a series of lipophilic tertiary ammonium derivatives susceptible to interact with its active site, and possessing a variety of structures and biological properties, have been examined. This included the agronomical $\mathrm{N}$-substituted morpholine fungicides tridemorph (11) and fenpropimorph (12) [13,14], the fungicide AY-9944 (13) [39], the human receptor $\sigma$ ligand SR31747A (14) [40], the high affinity human emopamil-binding protein (EBP) ligand trifluoperazine (15) [17], the estrogen receptor modulator tamoxifen (16) [41], and the rationally designed 8-aza-decalins (17), (18) and (19). Table 5 provides a summary of the dose-response curves obtained for in vitro inhibition of the recombinant plant $8,7 \mathrm{SI}$ by these compounds, allowing the corresponding $I_{50}$ values to be determined. In addition, we similarly determined $I_{50}$ values for a number of these compounds for the yeast and murine 8,7SIs. These data and those found in the literature for in vitro inhibition of yeast and animal 8,7SIs are shown in Table 5.

By examining first at $\mathrm{pH}=7.5$ the cationic azadecalin [17] and the corresponding neutral amide analogue [19], yielding $I_{50}$ values of $0.85 \mu \mathrm{M}$ and more than $100 \mu \mathrm{M}$, respectively, it was confirmed that the HEI analogues function with a charged ammonium group. Six ammonium-derivatives were potent inhibitors of Zm8,7SI with $\mathrm{I}_{50}$ values in the range 0.1-2.0 $\mu \mathrm{M}$ and $\mathrm{I}_{50} / \mathrm{K}_{\mathrm{m}}(\mathbf{1}$ or $\mathbf{3})=2.10^{-4}-2 \cdot 10^{-2}$. Two ammonium-derivatives (15) and (16) with a higher molecular weight and less structural flexibility were much poorly accomodated, 
yielding $\mathrm{I}_{50}$ values of 8.5-10 $\mu \mathrm{M}$. The lower inhibition by these two ammonium-derivatives indicates that the binding site has a limited tolerence in terms of size and flexibility of the lipophilic domain of the HEI analogues.

Our in vitro assay revealed the potent inhibition of the plant $8,7 \mathrm{SI}$ by the $\sigma$-ligand SR31747 (14) $\left(I_{50}=0.1 \mu \mathrm{M}\right)$ which is comparable to the inhibition of the recombinant yeast $\left(I_{50}=0.6 \mu \mathrm{M}\right)[16]$ and mammalian $8,7 \mathrm{SI}\left(I_{50}=0.40 \mu \mathrm{M}\right)$ by this derivative (Table 5). These data indicate that the diverse 8,7SIs contain a high-affinity binding site for the $\sigma$-ligand SR31747. In addition, the observed affinity of (14) is in the same order as that measured for the Zm8,7SI with HEI analogues $(\mathbf{1 7})$ and $(\mathbf{1 8})\left(I_{50}=0.85\right.$ and $0.10 \mu \mathrm{M}$ respectively), and (18) is a good inhibitor of the mammalian $\left(I_{50}=10 \mu \mathrm{M}\right)$ [42] and yeast $8,7 \mathrm{SI}\left(I_{50}=0.2 \mu \mathrm{M}\right)$. Moreover, we observed a similar affinity of trifluoperazine $(\mathbf{1 5})$ for the plant $8,7 \mathrm{SI}\left(I_{50}=10 \mu \mathrm{M}\right)$ and for the human $\operatorname{EBP}\left(I_{50}=7 \mu \mathrm{M}\right)$ [17], while it is a poor inhibitor of yeast $8,7 \mathrm{SI}\left(\mathrm{I}_{50}>500 \mu \mathrm{M}\right)$.

\section{Requirement of acidic amino-acid residues for $\mathrm{Zm} 8,7 \mathrm{SI}$ activity.}

Multiple sequence alignment of 8,7SI across seven species (Z. mays, O. sativa, A. thaliana, H. sapiens, M. musculus, R. norvegicus and S. cerevisiae (Figure 3) revealed that across all seven species, 8,7SIs show identity for a variety of amino acids. In addition, the plant and animal 8,7SIs show additional identities which are not shared with the yeast enzyme.

Based on the catalytic mechanism of $8,7 \mathrm{SI}$, good candidates for both the proton donor and the proton acceptor would be acids as previously suggested [4]. To identify acid residues that might be critically important for the proton delivery and (or) abstraction in the plant sterol isomerase, we mutated a number of acidic residues conserved in the 8,7 SIs between plants, animals and yeast, or conserved only between plants and animals, so that they could no longer serve as proton-donating or accepting residues. In addition, we also mutated a conserved histidine residue which could function as a proton-donating or accepting residue during the isomerization reaction. Moreover, previous studies from our laboratory emphasized the importance of electrostatic interactions during the binding of carbocationic HEI analogue inhibitors to the catalytic site [36]. The nature of the amino acid residue of the enzyme interacting with these inhibitors is not known, but it could be a delocalized carboxylate anion such as the two aspartate and glutamate residues which have been shown to be obligatory for ammonium-derivatives binding of the $\sigma_{1}$ receptor [43]. 
In order to have minimal effects on secondary structure, we chose to mutate the different amino-acid by sterically conservative hydrophobic and electrically neutral residues. Thus we neutralized residues i) $\mathrm{H} 74$, E78, and E121 which are conserved in animals, plants and yeast and ii) E102, D107, D114, and D170 which are conserved only in animals and plants. The mutants proteins (H74L, E78V, E102V, D107V, D114V, E121V and D170V) were expressed in erg 2 null mutant and the mutated isomerases were assayed in vivo by sterol analysis and quantification of $\Delta^{5,7}$-sterols. In addition, the activities of the recombinant plant 8,7SIs were examined directly in vitro in the corresponding yeast microsomal preparations.

The effects of these mutations on in vivo and in vitro activities of Zm8,7SI are shown in Table 6. In four out of the seven mutants, H74L, E78V, D107V and E121V, replacement of the proton delivering residue by leucine or valine totally eliminated the activity both in vivo, since neither $\Delta^{5,7}$ - nor $\Delta^{7}$-sterols were detected, and in vitro, since no 8,7SI activity could be detected (Table 6), indicating that these residues were essential for the enzyme activity. The other mutants, D114V and D170V exhibited similar sterol profiles as the wild-type and an in vitro activity that was about $60 \%$ of the activity of the wild-type enzyme. Therefore, these residues are not essential for the catalysis but contribute to the activity through conformational or other effects.

For the mutants that failed to complement it was conceivable that conservation of fonctionality and charge at these positions might be sufficient for 8,7SI activity. We explored this possibility in one case, E78, and changed this residue to a number of other residues, such that it could either no longer serve as a general acid or its $\mathrm{pK}$ would be significantly perturbed. We constructed 5 additional mutants : mutant E78D, E78H, E78R, E78K and E78Q. None of these mutants complemented erg2, suggesting that both fonctionality and length of the side chain of the residue 78 are critical for $8,7 \mathrm{SI}$ activity.

\section{Involvement of critical tryptophan residues for $\mathrm{Zm8,7SI}$ activity.}

Electron-rich aromatic amino acids have been suggested in general terms as particular stabilizers of intermediate carbocations [44]. The crystal structure of the hopene cyclase indeed revealed that several tryptophanes and phenylalanines residues were well positioned to stabilize different cations of the cyclization cascade [45]. Thus, we mutated i) W183 which is mostly conserved in animals, plants and yeast, ii) W66, W100, W193 which are conserved 
only in animals and plants and iii) W67 and W205 which are not conserved, by leucine residues.

In two out of the six mutants, W66L and W193L, replacement of the tryptophane residue by leucine totally eliminated the activity both in vivo and in vitro (Table 6) indicating that these residues were essential for the enzyme activity. The mutants, W67L, W100L, W183L and W205L exhibited similar sterol profiles as the wild-type and an in vitro activity that was 60 to $100 \%$ of the activity of the wild-type enzyme. Therefore, these residues are not essential for the catalysis but contribute to the activity through conformational or other effects.

An hydroxyl function at residue 124 is needed for maximal binding of the enzyme-substrate complex.

We looked for conserved residues that could be involved in the binding of the $3 \beta-\mathrm{OH}$ group of the sterol substrate at the end of the binding pocket. Some of the aforementioned carboxyl residues could form an hydrogen bond with the $3 \beta$-hydroxyl group of the sterol substrate. For exemple, the estrogen receptor donates a hydrogen bond to a glutamate residue [46]. Moreover, in Mycobacterium tuberculosis sterol 14 $\alpha$-demethylase, an aspartate residue is hypothesized to form a hydrogen bond with the $3 \beta-\mathrm{OH}$ [47]. However, in Candida albicans sterol $14 \alpha$-demethylase, a threonine residue was predicted to form a hydrogen bond with the $3-\mathrm{OH}$ of the sterol substrate and helped to locate it in the active site [48]. Thus, we mutated the hydroxy-containing residue T124 conserved in all organisms (Figure 3).

While replacement of threonine 124 by a functionally conservative serine residue in mutant T124S led to a sterol profile similar to the wild-type, its replacement by an hydrophobic isoleucine residue in mutant T124I led to a strong decrease in $\Delta^{5,7}$-sterol content $(6 \%)$, absence of $\Delta^{7}$-sterols and high accumulation of $\Delta^{8}$-sterols (Table 6). Because this mutation led in vivo to a sterol profile clearly dictinct from both those of wild-type-like or inactive mutants, we characterized more precisely its enzymatic kinetics properties in vitro. The fact that the $K_{m}$ for mutant T124I, is increased 25 -fold $(3.03 \mathrm{mM})$ indicates that $\mathrm{Thr} 124$ contributes to the stabilization of the enzyme-substrate complex in the ground state. In contrast, $\mathrm{Vmax} / \mathrm{Km}$ was decreased about only 3 -fold, indicating that Thr124 has a minor role in stabilizing the transition state of a rate-controlling step of the 8,7SI reaction, which is much less destabilized in T124I. The result is a substantial decrease of the activation energy to reach 
the transition state thus leading to a significant improvement of the isomerase maximum rate [49] (101nmol.mg.h $\left.\mathrm{h}^{-1}\right)$ in mutant T124I.

\section{Functional diversity between the plant and yeast 8,7SIs.}

To know whether sterol 8,7-isomerization reaction in plant and yeast would involve identical essential amino-acid residues, we mutated in Saccharomyces cerevisiae 8,7SI conserved residues corresponding to amino-acid residues found to be essential or important for the Zm8,7SI activity. Thus yeast mutants H69L, E73V, E116V and T119I, corresponding respectively to $\mathrm{H} 74, \mathrm{E} 78, \mathrm{E} 121$ and $\mathrm{T} 124$ in Zm8,7SI, were constructed and analyzed as described above. Mutants H69L, E73V and E116V exhibited similar sterol profiles as the wild-type yeast 8,7SI (Table 6). Therefore, in contrast to Zm8,7SI and animal 8,7SI, acidic amino-acid residues at these positions, as well as at position 102 corresponding to D107 in $Z m 8,7$ SI, are not essential for the yeast 8,7SI catalytic activity (Table 7). In addition, table 7 shows also that two essential Zm8,7SI tryptophane residues (W66 and W193) were also not conserved in $S c 8,7$ SI.

In contrast, threonine 119 corresponding to T124 in Zm8,7SI was found to be essential also for Sc8,7SI activity (Tables 6 and 7).

\section{Expression of mutated Zm8,7SIs.}

Because it is an integral membrane-bound protein, $\mathrm{Zm8}$,7SI has not yet been purified allowing production of antibodies to examine its expression levels in the microsome extracts used herein. However, two mutational studies of membrane-bound enzymes of the postsqualene sterol synthesis performed in similar yeast expression systems as ours (erg2 and erg6 mutants), indicated no major differences in the expression level of the different mutants and wild type enzymes [24,50]. To express our different 8,7SI mutants in the yeast erg2 strain we used a multicopy plasmid containing a strong promotor (yeast $A D H 1$ promotor). These conditions should favour the similar expression of these mutants. To check protein accumulation from wild type and mutated Zm8,7-SI cDNAs, we constructed for a number of them the corresponding 8,7SI proteins fused to an N-terminal FLAG epitope $(\mathrm{Z} m$ FLAG8,7SI). Because of the amount of work needed to develop FLAG constructs corresponding to all mutations, we developped FLAG constructs only for a sub-set of essential (D107V) and non-essential (D114V, D170V) acidic residues, as well as for essential 
(W193) and non-essential (W205L) tryptophane residues in addition to the WT enzyme. The microsome extracts from the corresponding transformed yeast cells were submitted to SDS/PAGE followed by Western blot analysis using commercial anti-FLAG serum (Figure 4). There is evidence that all mutated and wild-type FLAG8,7SI proteins did accumulate. However there appears to be some differences in the level of accumulation which could be due to the yeast culture conditions which were not optimized for heterologous protein production.

Considering these data together, it seems unlikely that the lack of activity in the mutated 8,7SIs would result from lack of expression or accumulation in the yeast membranes.

\section{DISCUSSION.}

The predicted amino-acid sequence of the present $Z m 8$,7SI confirms that the plant 8,7SIs, including the Arabidopsis isomerase [18], are much more closely structurally related to the animal 8,7SI protein [17] than to the ERG2 protein from S.cerevisiae [19].

In vitro kinetics with a variety of potential substrates revealed that $4 \alpha$-methylsterol (3) has the highest specificity constant $\left(\mathrm{V}_{\max } / \mathrm{K}_{\mathrm{m}}\right)$ and thus is the preferred substrate of the recombinant maize 8,7SI. The data is in agreement with previous in vivo results obtained in plant cells treated with the 8,7SI inhibitor AY9944, indicating an accumulation of $4 \alpha$-methyl$5 \alpha$-ergosta-8,24(24 $)$-dien-3 $\beta$-ol (3) and $4 \alpha$-methyl-5 $\alpha$-stigmasta-8,24(24 $\left.4^{1}\right)$-dien-3 $\beta$-ol in addition to a variety of $\mathrm{C} 4$-demethylated- $\Delta^{8}$-sterols $[1,31]$. In contrast, substrate specificity studies with membrane-bound rat-liver isomerase indicated that the isomerization occurs primarily after complete nuclear demethylation in the formation of cholesterol from lanosterol [38]. In addition, fecosterol (24-methylene- $\Delta^{8}$-cholestenol) was shown to be an isomerase substrate using yeast extracts [8]. Such unique substrate specificity of the plant enzyme is unusual when data for the human and fungal enzymes are compared. The distinct substrate specificities observed for the plant as opposed to human/fungal 8,7SIs presumably reflects the early divergence of the sterol biosynthetic pathway in the plant kingdom and underlines the molecular diversity of 8,7 SI substrates in plants, yeast and animals.

The potent inhibition of maize 8,7SI by the $\sigma$-ligand SR31747A is in good agreement with the previously reported inhibition by other $\sigma$-ligands of the production of ergosterol in erg2 mutant complemented with an Arabidopsis 8,7SI cDNA [18]. Incidentally, drugs such as 
the $\sigma$-ligand SR31747A which inhibit the activity of the $\sigma$ receptor and yeast 8,7SI [16], cause defects in a variety of cellular processes including immunosuppressive effects such as inhibition of graft rejection or lymphocyte proliferation [51]. As shown particularly for Zm8,7SI, the striking ability of 8,7 SIs from different sources to bind a variety of structurally distinct lipophilic tertiary ammonium derivatives with various biological properties is remarkable. It is worth noting that SR31747 (14) is structurally not related to the sterol substrate nor to the rationally designed HEI analogs (17) and (18), although the protonated form of its tertiary amine function presumably interacts with the active site domain that stabilizes the putative HEI. The data underline the primary importance of electrostatic interactions in the binding of such tertiary ammonium derivatives to the isomerase. Accordingly, human 8,7SI (human EBP), has been shown to be able to bind a variety of structurally distinct drugs, suggesting an intimate pharmacological relationship among EBP, $\operatorname{Erg} 2 \mathrm{p}$ and $\sigma_{1}$-receptor [11]. As previously suggested for human 8,7SI [11], the propensity to bind structurally distinct compounds could also be related to the presence of a sterol binding site in the protein. Indeed, plants contain proteins able to bind non-specifically a variety of lipid derivatives including fatty-acids and sterols [52], and the multidrug resistance protein involved in extrusion of xenobiotics takes part in cholesterol biosynthesis [53].

Our in vivo and in vitro mutational analysis of recombinant 8,7SIs clearly show that acidic residues E78, D107 and E121, and H74 are essential for Zm8,7SI enzymatic activity while no essential acidic residue was found in the homologous positions in $S c 8$,7SI. In contrast, the corresponding EBP amino acid residues E81, D108, E122 and H77 have been shown to be also critical for the in vivo 8,7SI activity of the human EBP albeit the mutations were not tested directly, in vitro, on the enzymatic activity [24]. In the plants and animals 8,7SIs, D107 lies within a sequence box that is completely conserved in a cytoplasmic domain. In contrast H74, E78 and E121 are located into two putative transmembrane segments. H74, E78 and E121 could include the two obligatory distinct residues that deliver and receive a proton during the trans addition-elimination of hydrogens atoms during the plant and animal 8,7SIs catalytic process. Incidentally, it has been demonstrated that the initial protonation of the carbon-carbon bond in the squalene hopene cyclase involves a carboxylic acid [45].

For the mutants that failed to complement, we could show in the case of residue E78 that the functionality as well as the length of the side chain residue are critical for $8,7 \mathrm{SI}$ activity. The aforementioned detailed catalytical mechanism of the 8,7SI suggests a precise 
organization within the Michaelis complex to preferentially add a proton on a C8(9) double bond rather than on a $\mathrm{C} 14$ double bond, and to rigidly control the stereochemistry of the proton abstraction at $\mathrm{C}$. It would be conceivable to disturb the precise molecular interactions of the enzyme-substrate complex by changes in the nature or the distance of the catalytical amino-acid residues to produce an inactive enzyme.

Our data clearly show that tryptophane residues W66 and W193 play crucial roles in the $Z m 8$,7SI, either for the correct folding of the protein, or for the catalytical process. In this latter case they could possibly be involved in the stabilization of the C8 carbocationic intermediate. In accord with this hypothesis, W66 and W193 are located into two putative transmembrane segments. Substitution of the homologous residues in the human $8,7 \mathrm{SI}$ by alanine was shown to reduce also dramatically the amount of $\Delta^{5,7}$-sterols in the corresponding yeast transformants compared to the wild-type isomerase [24]. However, no aromatic residue was found in the homologous positions in the yeast isomerase (Table 7), underlying the functional diversity of the different 8,7 SIs.

Suppression of the hydroxyl function at residue 124 apparently decreased more substantially the stability of the enzyme-substrate complex in the ground state than in the transition state. The data could reflect the formation of a hydrogen bond between threonine 124 and the $3-\mathrm{OH}$ of the sterol, helping to dock the sterol in the active site in the ground-state as previously proposed in the case of the Candida albicans sterol $14 \alpha$-demethylase [48]. This residue could have a similar function in the different 8 ,7SIs since it is important or critical in all of them (Table 7). Incidentally, a more important role for the interaction of the $3 \beta$ hydroxyl group with a specific amino-acid for initial substrate binding than for transition state stabilization would be in accord with previous studies showing that a number of structural features that are critical for binding of the sterol substrates in the ground state (such as the $3 \beta$ hydroxyl group) play a minor role for binding of transition state analogs [36].

The complementing mutations obtained herein did not alter the sensitivity of the transformed yeast strain erg2 to the inhibitors azadecaline [18] and SR31747 [14], and they showed a similar sensitivity to nystatin as the wild-type, as observed by spotting the corresponding cells on media with or without these inhibitors. In contrast, the noncomplementing mutants affected in essential amino-acids were all insensitive to nystatin and, in addition, exhibited a significant increase in sensitivity to [18] and [14] (EC50 decreased 5to 10 -fold, data not shown). It has been previously shown that ERG2 is not an essential gene in contrast to ERG24 coding for the sterol C-14 reductase, and that overexpression of $E R G 2$ 
does not lead to fenpropimorph resistance while overexpression of ERG24 does [54]. The increased sensitivity of non-complementing mutants to [18] and [14] could thus reflect a higher concentration of these inhibitors available for blockade of endogenous C14-reductase in the yeast cells because of absence of binding to the mutated $Z m 8$,7SI. These data would be consistent with the hypothesis that mutations found to be critical for Zm8,7SI activity also lower the binding of these lipophilic tertiary ammonium derivatives to the enzyme. This hypothesis of an intimate structural relationship between the catalytic site and the inhibitors binding domain is in accord with their function as putative HEI analogues and would need a combination of binding assay studies of a radiolabelled inhibitor with the present site-directed mutagenesis study.

Biochemical analysis of A. thaliana hydl mutant strongly affected in embryonic development $[26,55]$, revealed deficiency in 8,7SI activity. The hyd1-E508 allele was found to encode a D102N substitution in 8,7SI that corresponds to the D107V mutation in Z.mays, that we found also essential for the maize isomerase. All the essential amino acids found in the present work are conserved between Z.mays and other plant 8,7SIs including A.thaliana 8,7 SI. Thus, we think that the conclusions obtained with the present maize mutants could be extrapolated with confidence particularly to the Arabidopsis isomerase and the data used for appropriate Arabidopsis plant mutants for further characterization.

This first series of mutants of plant sterol $8,7 \mathrm{SI}$ in this work has allowed the identification of 6 essential amino-acid residues for plant 8,7SI activity by in vivo complementation of the yeast erg2 mutant and corroboration of the results by direct in vitro measurement of the 8,7SI activity in the corresponding microsomes extracts. The absence of any structural information for this membrane associated enzyme limits our ability to verify the hypotheses about the specific role played by the essential amino-acid residues identified herein. However, it is likely that they are located at the substrate binding domain of the active-site of the enzyme.

Remarkably, the critical residues identified in the plant 8,7SI are conserved and also crucial in the animal 8,7SI, while they are either not essential or not conserved in the yeast 8,7SI. These data underline the functional homology between the plant and animal 8,7SIs, and their high divergence with the yeast 8,7SI, in accord with their structural diversity and the distinct stereochemistry of their mechanisms. Moreover, enzymes involved in postsqualene sterol biosynthesis in higher plants generally share amino-acid identity ranging from $28 \%$ to $38 \%$ with their corresponding S. cerevisiae counterparts [1]. In contrast, with less than $15 \%$ identity, clear distinct substrate specificities and non conserved essential amino-acid residues, 
it appears that the 8,7-isomerization step is performed by completely different enzymes in higher plants and animals on one hand, and in S. cerevisiae and probably most fungi on the other hand. This finding, however is not unprecedented in the pathway since no orthologs of sterol C24 $\left(24^{1}\right)$ reductase isomerase from A.thaliana has been reported in the S. cerevisiae genome $[1,56]$. In addition to the present work, further structural informations about the active site of the fungal, plant, and mammalian 8,7SI could provide a basis for rational design of more efficacious and specific antifungal agents in addition to a better insight into the molecular mechanism of 8,7-sterol isomerase.

\section{ACKNOWLEDGEMENTS}

We are indebted to Dr. M. Bard, Indiana University, Indianapolis, USA, for providing the yeast mutant erg2. The authors warmly thank Dr.Geneviève Genot for her help in western blot analysis. We are grateful to Dr. G. Loison, Sanofi-Aventis Recherche-Developpement, Labège, France, for providing SR31747 and the yeast strain $\Delta$ erg2pEMR1235. We acknowledge Dr. Marc Fischer for help in editing the manuscript.

\section{Abbreviations.}

$t_{R}$ : relative retention time to cholesterol in gas chromatography ; GC-MS : coupled gaschromatography mass-spectroscopy $; \hat{I}_{50}$ : Inhibitor concentration required to reduce the reaction velocity one-half; 


\section{REFERENCES}

1. Benveniste, P. (2004) Biosynthesis and accumulation of sterols. Annu.Rev. Plant Physiol. Plant Mol. Biol. 55, 429-457.

2. Bouvier, F., Rahier, A., and Camara, B. (2005) Biogenesis, molecular regulation and function of plant isoprenoids. Prog. Lipid Res. 44, 357-429.

3. Lees, N.D., Skaggs, B., Kirsch, D.R., and Bard, M. (1995) Cloning of the late genes in the ergosterol biosynthetic pathway of Saccharomyces cerevisiae. Lipids 30,221-226.

4. Wilton, D.C., Rahimtula, A.D., and Akhtar, M. (1969) The reversibility of the delta8cholestenol-delta7-cholestenol isomerase reaction in cholesterol biosynthesis. Biochem. J. 114, 71-73

5. Akhtar, M., Rahimtula, A.D., and Wilton, D.C. (1970) The stereochemistry of hydrogen elimination from $\mathrm{C} 7$ in cholesterol and ergosterol biosynthesis. Biochem. J. 117, 539-542.

6. Caspi, E., and Ramm, P.J. (1969) Stereochemical differences in the biosynthesis of C27 - $\Delta$ 7-steroidal intermediates. Tetrahedron Letters 10, 181-185.

7. Bimpson, T., Goad, L.J., and Goodwin, T.W. (1969). The stereochemistry of hydrogen elimination at C-7,C-22 and C-23 during the conversion of cholesterol (cholest-5-en-3 beta-ol) into cholesta-5,7,22-trien-3 beta-ol by Tetrahymena pyriformis. Biochem. J.. 1969, 857-858.

8. Yabusaki, Y., Nishino, T. Ariga, N., and Katzuki, H. (1979) Studies on $\Delta^{8}-\Delta^{7}$ isomerization and methyl transfer of sterols in ergosterol biosynthesis of yeast. J. Biochem. (Tokyo) 85, 1531-1537.

9. Soustre, I., Dupuy, P.H., Silve, S., Karst, F. and Loison, G. (2000) Sterol metabolism and ERG2 gene regulation in the yeast Saccharomyces cerevisiae. FEBS Lett. 470,102-106.

10. Rahier, A. and Taton,M. (1997) Fungicides as tools in studying postsqualene sterol synthesis in plants. Pestic.Biochem.Physiol. 57, 1-27.

11. Moebius, F.F., Reiter, R.J., Bermoser, K., Glossmann, H., Cho, S.Y., and Paik, Y-K. (1998) Pharmacological analysis of sterol $\Delta 8-\Delta 7$ isomerase proteins with $\left[{ }^{3} \mathrm{H}\right]$ ifenprodil. Mol. Pharmacol. 54, 591-598. 
12. Baloch, R.I., and Mercer, E.I. (1987) Inhibition of sterol $\Delta^{8}-\Delta^{7}$-isomerase and $\Delta^{14}$ reductase by fenpropimorph, tridemorph and fenpropidin in cell-free enzyme systems from Saccharomyces cerevisiae. Phytochemistry 26, 663-668.

13. Konig, K.H., Pommer, E.H., and Sanne, W. (1965) N-Substituted Tetrahydro-1,4oxazines - A New Class of Fungicidal Compounds. Angew. Chem. Int.Ed. 4, 336-341.

14. Himmerle, W., and Pommer, E.H. (1980) 3-phenylpropylamines, a new class of systemic fungicides. Angew. Chem. Int.Ed. 19, 184-189

15. Rahier, A., Taton, M., Schmitt, P., Benveniste, P., Place, P., and Anding, C. (1985) Inhibition of $\Delta^{8}-\Delta^{7}$-sterol isomerase and of cycloeucalenol-obtusifoliol isomerase by N-benzyl-8-aza-4 $\alpha, 10$-dimethyl-trans-decal-3 $\beta$-ol, an analogue of a carbocationic high energy intermediate. Phytochemistry 24, 1223-1232.

16. Silve, S., Leplatois, P., Josse, A., Dupuy, P.H., Lanau, C., Kaghad, M., Dhers, C., Picard, C., Rahier, A., Taton, M., Le Fur, G., Caput, D., Ferrara, P., and Loison, G. (1996) The immunosuppressant SR 31747 blocks cell proliferation by inhibiting a steroid isomerase in Saccharomyces cerevisiae. Mol. Cell. Biol. 16, 2719-2727.

17. Silve, S., Dupuy, P.H., Labit-Lebouteiller, C., Kaghad, M., Chalon, P., Rahier, A., Taton, M., Lupker, J., Shire, D., and Loison, G. (1996) Emopamil-binding protein, a mammalian protein that binds a series of structurally diverse neuroprotective agents, exhibits $\Delta 8-\Delta 7$ sterol isomerase activity in yeast. J. Biol. Chem. 271, 2424-22440.

18. Grebenok, R.J., Ohnmeiss, T.E., Yamamoto, A., Huntley, E.D., Galbraith, W., and Della Penna, D. (1998) Isolation and characterization of an Arabidopsis thaliana C-8,7 sterol isomerase; functional and structural similarities to mammalian C8,7sterol isomerase/emopamil-binding protein. Plant Molecular Biology 38, 807-815.

19. Ashman, W.H., Barbuch, R.J., Ulbright, C.E., Jarrett, H.W., and Bard, M. (1991) Cloning and disruption of the yeast C-8 sterol isomerase gene. Lipids 26, 628-632

20. Hanner, M., Moebius, F. F., Weber, F., Grabner, M., Striessnig, J., and Glossmann, H. (1995) Phenylalkylamine $\mathrm{Ca}^{2+}$ antagonist binding protein. Molecular cloning, tissue distribution, and heterologous expression. J. Biol. Chem. 270, 7551-7557.

21. Braverman, N., Lin, P., Moebius, F. F., Obie, C., Moser, A., Glossmann, H., Wilcox, W. R., Rimoin, D. L., Smith, M., Kratz, L., Kelley, R. I., and Valle, D. (1999) Mutations in the gene encoding 3 beta-hydroxysteroid-delta 8, delta 7-isomerase cause X-linked dominant Conradi-Hünermann syndrome. Nat Genet. 22, 291-294. 
22. Derry, J. M., Gormally, E., Means, G. D., Zhao, W., Meindl, A., Kelley, R. I., Boyd, Y., and Herman, G. E. (1999) Mutations in a delta 8-delta 7 sterol isomerase in the tattered mouse and x-linked dominant chondrodysplasia punctata. Nat. Genet. 22, 286-290.

23. Grange, D. K., Kratz, L. E., Braverman, N. E., and Kelley, R. I. (2000) Child syndrome caused by deficiency of 3beta-hydroxysteroid-delta8, delta7-isomerase. Am. J. Med. Genet. 90, 328-335.

24. Moebius, F.F., Soellner, K.E.M., Fiechtner, B., Huck, C.W., Bonn, G., and Glossmann, H. (1999) Histidine77, glutamic acid81, threonine126, asparagine194, and tryptophan 197 of the human emopamil binding protein are required for in vivo sterol $\Delta^{8}-\Delta^{7}$ isomerization. Biochemistry 38, 1119-1127.

25. Moebius F.F., Reiter, R.J., Hanner, M., and Glossmann, H. (1997) High affinity of sigma $_{1}$-binding sites for sterol isomerization inhibitors: evidence for a pharmacological relationship with the yeast sterol C8-C7 isomerase. Br J Pharmacol 121, 1-6.

26. Souter, M, Topping, J., Pullen, M., Frimi, J., Palme, K., Hackett, R., Grierson, D., and Lindsey, K. (2002) Hydra mutants of arabidopsis are defective in sterol profiles and auxin and ethylene signaling. The Plant Cell 14, 1017-1031.

27. Taton, M., Benveniste, P., and Rahier, A.(1986) N-[(1,5,9)-trimethyldecyl]-4a,10dimethyl-8-aza-trans-decal-3 $\beta$-ol, a novel potent inhibitor of 2,3-oxidosqualene cycloartenol and lanosterol cyclases. Biochem. Biophys.Res. Commun. 138, 764-770.

28. Vernet, T., Dignard, D. and Thomas, D.Y. (1987) A family of yeast expression vectors containing the phage 11 intergenic region. Gene 52, 225-233.

29. Gietz, D., St Jean, A., Woods, R.A. and Schiestl, R.H. (1992) Improved method for high efficiency transformation of intact yeast cells. Nucleic Acid Res. 20, 1425-1432.

30. Rahier, A. and Benveniste P. (1989) Mass spectral identification of phytosterols. In Analysis of sterols and other significant steroids (Nes, W.D. and Parish, E., Eds) pp. 223-250, Academic Press, New York.

31. Schmitt, P., and Benveniste, P., (1979) Effect of AY-9944 on sterol biosynthesis in suspension cultures of bramble cells. Phytochemistry 18, 445-450

32. Darnet, S., and Rahier, A., (2003) Enzymological properties of sterol-C4-methyloxidase of yeast sterol biosynthesis. Biochem. Biophys. Acta 1633, 106-117 
33. Taton, M., and Rahier, A., (1991) Properties and structural requirements for substrate specificity of cytochrome P-450-dependent obtusifoliol $14 \alpha$-demethylase from maize (Zea mays) seedlings. Biochem. J. 277, 483-492

34. Taton, M., Benveniste, P. and Rahier, A., (1989) Microsomal $\Delta^{8,14}$-sterol $\Delta^{14}$-reductase in higher plants. Characterization and inhibition by analogues of a presumptive carbocationic intermediate of the reduction reaction. Eur.J. Biochem. 185, 607-614.

35. Duggleby, R.G. (1984) Regression analysis of nonlinear Arrhenius plots: an empirical model and a computer program. Comput. Biol. Med. 14, 447-455.

36. Rahier, A, Taton, M., and Benveniste, P. (1990) Inhibition of sterol biosynthesis enzymes in vitro by analogues of high-energy carbocationic intermediates. Biochem .Soc. Trans. 18, 48-52.

37. Bradford, M. (1976) A rapid and sensitive method for the quantitation of microgram quantities of protein utilizing the principle of protein-dye binding. Anal. Biochem.72, 248-254.

38. Nes, W.D., Zhou, W., Dennis, A.L., Li, H., Jia, Z., Keith, R.A., Piser, T.M., and Furlong, S.T. (2002) Purification, characterization and catalytic properties of human sterol 8-isomerase. Biochem. J. 367, 587-599.

39. Dvornik, D., Kraml, M., Dubuc, J., Givner, M., and Gaudry, R. (1963) A Novel Mode of Inhibition of Cholesterol Biosynthesis. J. Am. Chem. Soc. 85, 3309.

40. Derocq, J.M., Bourrie, B., Segui, M., Le Fur, G., and Casellas, P. (1995) In vivo inhibition of endotoxin-induced pro-inflammatory cytokines production by the sigma ligand SR 31747. J Pharmacol. Exp. Ther. 272, 224-230.

41. Jordan, V.C. (2003) Tamoxifen: a most unlikely pioneering medicine. Nat. Rev.Drug.Discov.2, 205-213.

42. Gerst, N., Duriatti, A., Schuber, F., Taton, M., Benveniste, P., and Rahier, A. (1988) Potent inhibition of cholesterol biosynthesis in $3 \mathrm{~T} 3$ fibroblasts by $N$-[(1,5,9)trimethyldecyl]-4 $\alpha, 10$-dimethyl-8-aza-trans-decal-3 $\beta$-ol, a new 2,3-oxidosqualene cyclase inhibitor. Biochem. Pharmacol. 37, 1955-1964.

43. Seth, P., Ganapathy, M.E., Conway, S.J., Bridges, C.D., Smith, S.B., Casellas, P ?; and Ganapathy, V. (2001) Expression pattern of the type 1 sigma receptor in the brain and identity of critical anionic amino acid residues in the ligand-binding domain of the receptor. Biochem. Biophys. Acta 1540, 59-67 
44. Johnson, W.S., Lindell, S.D., and Steele, J. (1987) Rate enhancement of biomimetic polyene cyclizations by a cation-stabilizing auxiliary. J. Am. Chem. Soc. 109, 58525853.

45. Wendt, K.U., Lenhart, A., and Schulz, G.E. (1999) The structure of the membrane protein squalene-hopene cyclase at $2.0 \mathrm{~A}^{\circ}$ resolution.

46. Tanenbaum, D.M., Wang, Y., Williams, S.P., and Sigler, P.B. (1998) Crystallographic comparison of the estrogen and progesterone receptor's ligand binding domains. Proc. Natl. Acad. Sci. USA 95, 5998-6003.

47. Lepesheva, G.I., and Watermann, M.R. (2004) CYP51-the omnipotent P450. Mol. and Cell Endocrinology 215, 165-170.

48. Lamb, D.C., Kelly, D.E., Schunck, W-H., Shyadehi, A.Z., Akhtar, M., Lowe, D.J., Baldwin, B.C., and Kelly, S.L. (1997) The mutation T315A in Candida albicans sterol $14 \alpha$-demethylase causes reduced enzyme actvity and fluconazole resistance through reduced affinity. J. Biol. Chem. 272, 5682-5688.

49. Taton, M., Husselstein, T., Benveniste, P., and Rahier, A. (2000) Role of highly conserved residues in the reaction catalyzed by recombinant $\Delta^{7}$-sterol-C5(6)desaturase studied by site-directed mutagenesis. Biochemistry 39, 701-711.

50. Avelange-Macherel, M.H., Macherel, D., Wada, H., and Murata, N. (1995) Sitedirected mutagenesis of histidine residues in the delta 12 acyl-lipid desaturase of Synechocystis. FEBS Lett. 361, 111-114.

51. Carayon, P., Bouaboula, M., Loubet, J.F., Bourrie, B., Petitpretre, G.,Le Fur, G., and Casellas, P. (1995) The sigma ligand 31747 prevents the development of acute graftversus-host disease in mice by blocking IFN-gamma and GM-CSF mRANA expression. Int. J. Immunopharmacol.17, 753-761.

52. Osman, H., Mikes, M.-L., Ponchet, M , Marion, D., Prangé, T., Maume, B.F., Vauthrin, S. and Blein, J.-P. (2001) Fatty acids bind to the fungal elicitor cryptogein and compete with sterols. FEBS Lett. 489, 55-58

53. Metherall, J.E., and Huijan, L. (1996) Role of multidrug resistance P-glycoprotein in cholesterol biosynthesis. J. Biol. Chem. 271, 2634-2640.

54. Lai, M.H., Bard, M., Pierson, CA, AlaxanderJ.F., Goebl, M., Carter, G.T., and Kirsch, D.R. (1994) The identification of a gene family in the Saccharomyces cerevisiae ergosterol biosynthesis pathway. Gene 11, 41-49. 
55. Schrick, K., Mayer, U., Martin, G., Bellini, C., Kuhnt, C., Schmidt, J., and Jürgens, G. (2002) Interactions between sterol biosynthesis genes in embryonic development of Arabidopsis. Plant J. 31, 61-73.

56. Choe, S., Dilkes, B., Gregory, B.D., Ross, A.S., Yuan, H., Noguchi, T., Fujioka, S., Takatsuto, S., Tanaka, A., Yoshida, S., Tax, F.E., and Feldmann, K.A. (1999) The Arabidopsis $d w a r f 1$ mutant is defective in the conversion of 24-methylene-cholesterol to campesterol in brassinosteroid biosynthesis. Plant Physiol. 119, 897-907. 
Table 1. Sequence of the synthetic oligonucleotides used for molecular cloning and sitedirected mutagenesis of cDNA of the maize and yeast 8,7SI genes.

\begin{tabular}{|c|c|}
\hline Strain & Sense oligonucleotide sequence $\left(5^{\prime}-3^{\prime}\right)$ \\
\hline \multicolumn{2}{|c|}{ Cloning } \\
\hline $\mathrm{P} 1$ & ATAATATCTAGAATGGCCGCAGCGGCGTC \\
\hline $\mathrm{P} 2$ & ATAATACTCGAGTTATTTGGTCTTCTTCACCTTCACAGC \\
\hline $\mathrm{P} 3$ & $\begin{array}{l}\text { ATAATATCTAGAATGGACTACAAGGACGACGATGACAAGGCCGC } \\
\text { AGCGGCGGTCAATG }\end{array}$ \\
\hline
\end{tabular}

Site-directed mutagenesis

Zea mays

W66L CCGACCGTCTGCTCATGTGCTTGTGGGCATTCACAG

W67L CTGCTCATGTGCTGGTTGGCATTCACAGGGTTG

W66LW67L CCGACCGTCTGCTCATGTGCTTGTTGGCATTCACAGGGTTG

H74L GCATTCACAGGGTTGACCCTCATAATGATCGAGGGG

E78V CCCACATAATGATCGTGGGGCCCTTCGTC

E78D CCCACATAATGATCGATGGGCCCTTCGTCTTC

E78H CCCACATAATGATCCACGGGCCCTTCGTCTTCACTCC

E78R CCCACATAATGATCAGGGGGCCCTTCGTCTTCACTCC

E78K CCCACATAATGATCAAGGGGCCCTTCGTCTTC

E78Q CCCACATAATGATCCAGGGGCCCTTCGTCTTC

W100L CCCAATTTCTTTGATGAAGTTTTGAAAGAGTATAGTAAGGGAGAC

E102V GATGAAGTTTGCAAAGTGTATAGTAAGGGAGACTCTAGG

D107V GAGTATAGTAAGGGAGTCTCTAGGTATGTT

D114V GGTATGTTGCTAGGGTCACTGCAACTGTTACGG

E121V GCAACTGTTACGGTCGTAGGGATCACCGC

T124S CGGTCGAAGGGATCAGCGCTGTATTGGAAGGCCC

T124I CGGTCGAAGGGATCATCGCTGTATTGGAAGGCCC

D170V CACCGCGTACTTGGTCGGCTTCAACTTCTGG

W183L CGGCCCGTTCTACTTCTTGGCGTATTTCATTGGCGC

W193L GGCGCAAACAGCTTCTTGATCTGGATACCGATG

W205L CGCCATAAGGTCCTTGAAGAAAACTTGCGCCGC

Saccharomyces cerevisiae

H69L GACGCACTTGCCTCTCTATACGGGGACGAATACATC

E73V GCCTCTCATTACGGGGACGTGTACATCAACAGGTACG

E116V CCGCTGTTGGTACTGTTGGGCACACAGGTGTTCACTTTGCTGACG

T119I GGTACTGAAGGGCACATAGGTGTTCACTTTGCTGACG 
Table 2. GC-MS analysis of enzymatic products by the recombinant 8,7SI from Zea mays.

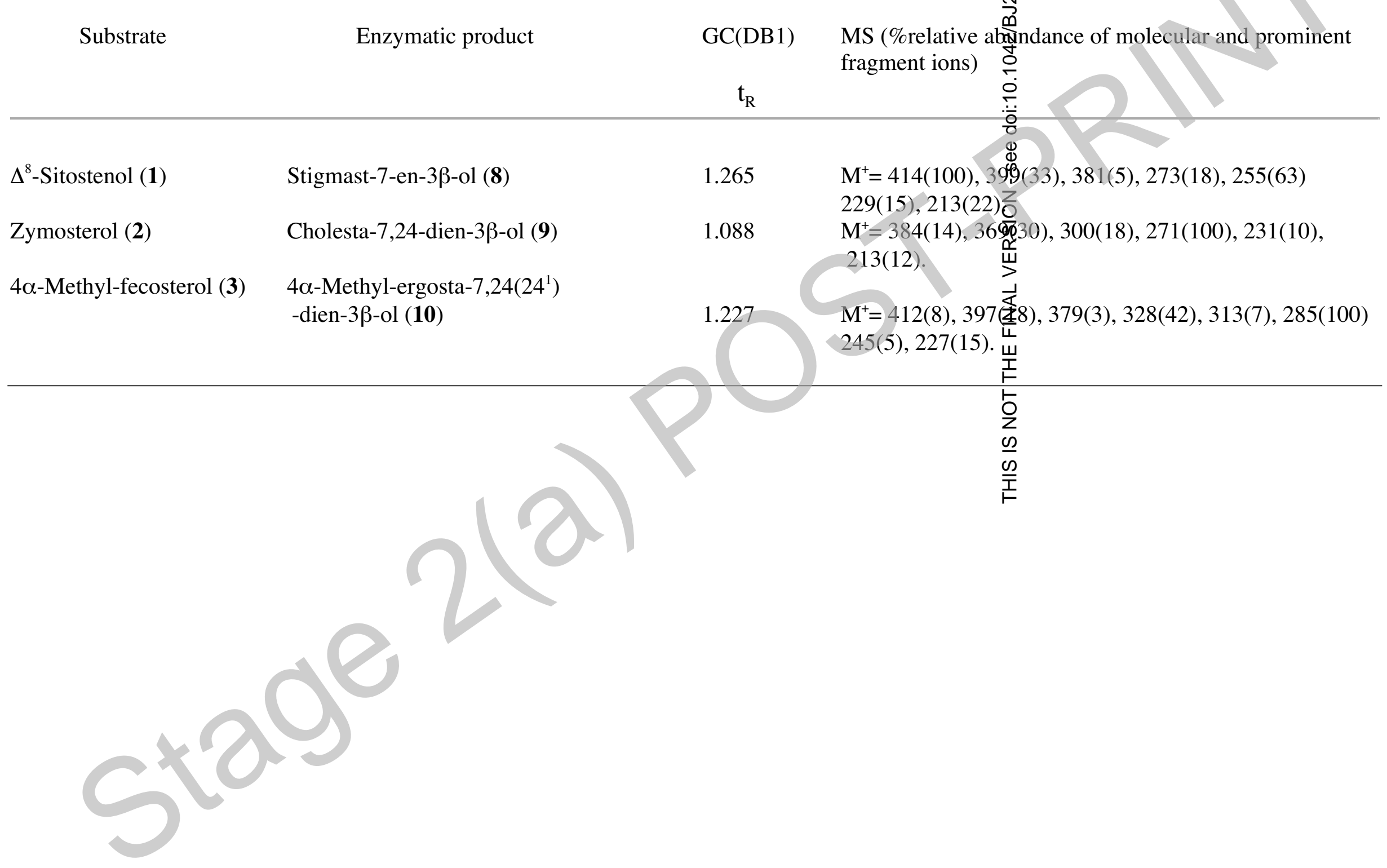


Table 3 : Sterol composition of mutant erg2 transformed with different plasmids.

\begin{tabular}{|c|c|c|c|c|}
\hline $\begin{array}{l}\text { Plasmid used to } \\
\text { transform erg } 2 \\
\text { null mutant }\end{array}$ & $\begin{array}{l}\text { total } \Delta^{5,7} \text {-sterols }{ }^{\mathrm{a}} \\
\text { or complementation } \\
\text { rate of erg } 2 \text { mutant }\end{array}$ & $\begin{array}{c}\text { total } \\
\Delta^{7} \text {-sterols }\end{array}$ & $\begin{array}{l}\text { total } \\
\Delta^{8} \text {-sterols }\end{array}$ & others sterols \\
\hline \multicolumn{5}{|c|}{$\%$ total sterol } \\
\hline pVT-Void & nd & nd & $95.6 \pm 0.4$ & $4.4 \pm 0.5$ \\
\hline pVT-Zm8,7SI & $56.7 \pm 1.3$ & $10.1 \pm 0.7$ & $25.4 \pm 0.6$ & $7.4 \pm 0.02$ \\
\hline pVT-ZmFLAG-8,7SI & $43.4 \pm 1.4$ & $9.2 \pm 0.8$ & $37.7 \pm 1.0$ & $9.7 \pm 0.4$ \\
\hline
\end{tabular}

Sterols were analyzed as described in the Materials and Methods. Data shown are means of 4 experiments \pm SD.

a) $\Delta^{5,7}$-sterols : ergosterol $\left(t_{R}=1.083\right) ; \Delta^{7}$-sterols : 7,22-ergosta-dienol $\left(t_{R}=1.136\right), 7,24\left(24^{1}\right)$, ergosta-dienol $\left(t_{R}=1.145\right)$; $\Delta^{8}$-sterols : 5,8,14,22-ergosta-tetraenol $\left(\mathrm{t}_{\mathrm{R}}=1.048\right), 5,8,22$-ergosta-trienol $\left(\mathrm{t}_{\mathrm{R}}=1.057\right)$, 8,22-ergosta-dienol $\left(\mathrm{t}_{\mathrm{R}}=1.064\right)$, $8,24\left(24^{1}\right)$-ergosta-dienol $\left(t_{R}=1.115\right)$, ergosta-8-enol $\left(t_{R}=1.121\right)$; others sterols : lanosterol $\left(t_{R}=1.205\right)$, 4,4-dimethylzymosterol $\left(\mathrm{t}_{\mathrm{R}}=1.215\right)$.

b) control plasmid without insert. nd : not detectable 
Table 4. Substrate specificity of recombinant maize sterol 8,7-isomerase and apparent kinetics parameters for productive substrates.

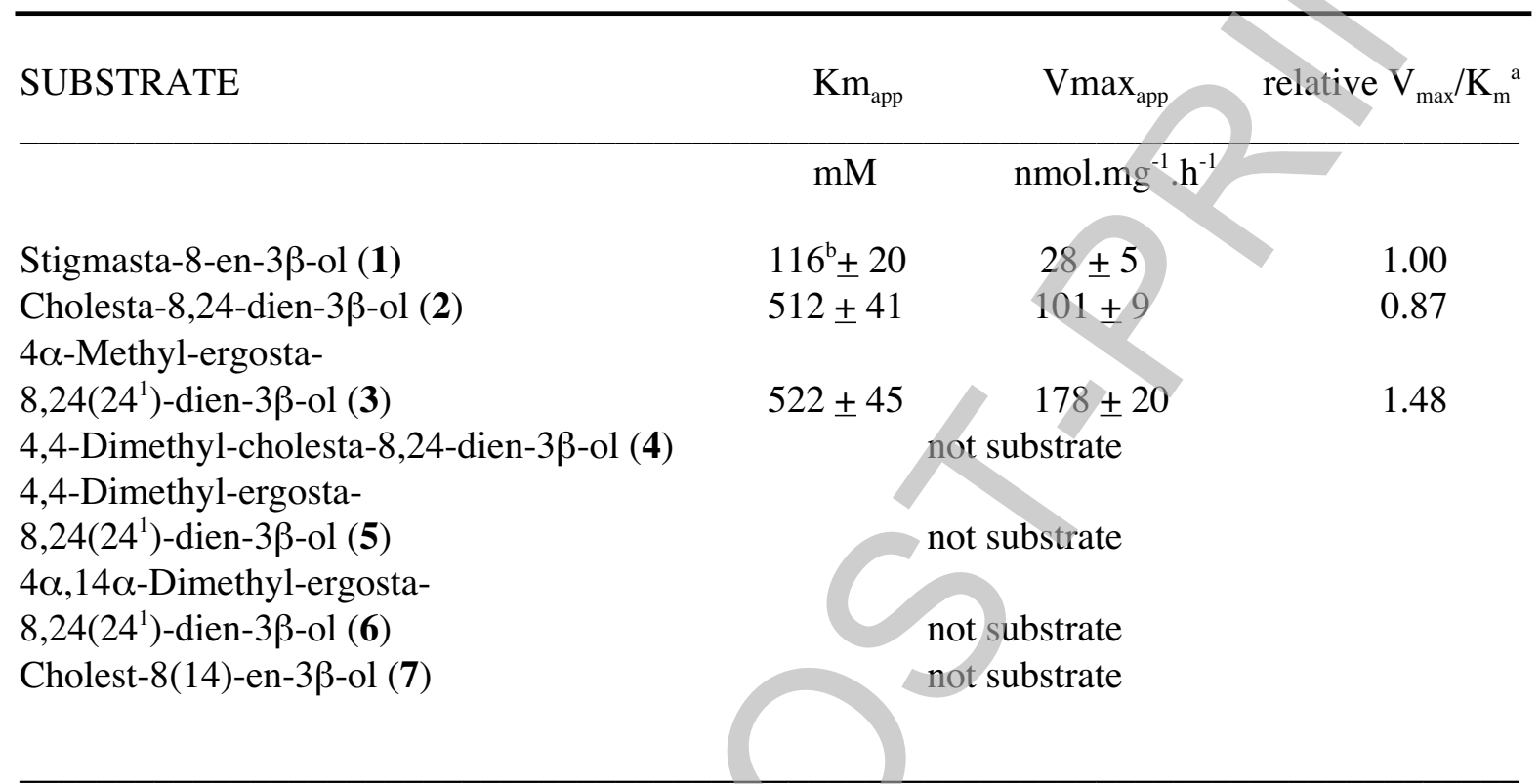

For each experiment, kinetic parameters of the different substrates were measured in the same microsomal preparation.

a) $\mathrm{V}_{\text {max }}=\mathrm{k}_{\text {cat }} \mathrm{x}$ [Enzyme concentration]; thus for two substrates, $\mathrm{A}$ and $\mathrm{B}$, using the same enzyme preparation: $\left(\mathrm{V}_{\max } / \mathrm{K}_{\mathrm{m}}\right)^{\mathrm{A}} /\left(\mathrm{V}_{\max } / \mathrm{K}_{\mathrm{m}}\right)^{\mathrm{B}}=\left(\mathrm{k}_{\mathrm{cat}} / \mathrm{Km}\right)^{\mathrm{A}} /\left(\mathrm{k}_{\mathrm{cat}} / \mathrm{Km}\right)^{\mathrm{B}}$.

b) Values represent the mean \pm S.D. of two independent experiments. 
Table 5 : In vitro inhibition by lipophilic tertiary ammonium derivatives of recombinant $Z m 8$, 7SI.

Comparison with data obtained with the animal and yeast 8,7 SIs.

\begin{tabular}{|c|c|c|c|}
\hline Enzyme source & maize $8,7 \mathrm{SI}$ & yeast $8,7 \mathrm{SI}$ & mammalian $8,7 \mathrm{SI}$ \\
\hline Inhibitor & & $I_{50}\left(10^{-6} M\right)$ & \\
\hline N-Geranyl-8-azadecalin (18) & $0.10^{\mathrm{a}}$ & 0.2 & $10[42]^{b}$ \\
\hline AY9944 (13) & 0.10 & ND & $16[11]$ \\
\hline SR31747 (14) & 0.10 & $0.60[16]$ & $0.4 \bigcirc$ \\
\hline Fenpropimorph (12) & 0.21 & 0.03 & ND \\
\hline N-Benzyl-8-azadecalin (17) & 0.85 & ND & $20 \quad[42]$ \\
\hline Tridemorph (11) & 1.7 & 1.0 & $3 \quad[11]$ \\
\hline Tamoxifen (16) & 8.5 & ND & $1.8[11]$ \\
\hline Trifluoperazine (15) & 10 & $>500 \quad[16]$ & 7 [16], $8[11]$ \\
\hline N-benzamido-decalin (19) & $>100:$ not inhibitory & ND & ND \\
\hline
\end{tabular}

a) 8,7SI activity and I50 values were determined as described in Experimental using a $100 \mu \mathrm{M}$ concentration of substrate $\Delta^{8}$-sitostenol (1). Values are the mean of two distinct determinations; the standard deviation was less than $15 \%$.

b) references refer to values taken from the literature.

ND : not determined or data not found in the literature. 
Table 6 : In vivo sterol composition and in vitro 8,7SI activity of erg2 null mutant and transformants carrying the wild-type or mutagenized Z.mays and S.cerevisiae 8,7-sterol isomerases.

\begin{tabular}{|c|c|c|c|c|c|}
\hline $\begin{array}{l}\text { Enzyme used to } \\
\text { transform erg } 2 \\
\text { null mutant }\end{array}$ & $\begin{array}{l}\text { total } \Delta^{5,7} \text {-sterols }{ }^{\mathrm{a}} \\
\text { or complementation } \\
\text { rate of erg2 mutant }\end{array}$ & $\begin{array}{c}\text { total } \\
\Delta^{7} \text {-sterols }\end{array}$ & $\begin{array}{c}\text { total } \\
\Delta^{8} \text {-sterols }\end{array}$ & others sterols & $\begin{array}{l}\text { Relative in vitro } \\
Z m 8,7 \text { SI activity }\end{array}$ \\
\hline erg2 null mutant & ND & ND & 97.7 & 2.3 & 0 \\
\hline \multicolumn{6}{|l|}{ Zea mays } \\
\hline wild-type & $56.6^{\mathrm{c}}$ & 10.1 & 25.4 & 7.4 & $100^{\mathrm{d}}$ \\
\hline H74L & ND & ND & 92.3 & 7.7 & 0 \\
\hline E78V,D,H,R,K,Q & ND & ND & 96.5 & 3.5 & 0 \\
\hline E102V & 50.4 & 8.4 & 34.8 & 6.0 & 90 \\
\hline D107V & ND & ND & 96.8 & 3.2 & 0 \\
\hline D114V & 37.2 & 6.0 & 50.0 & 9.8 & 57 \\
\hline E121V & ND & ND & 96.9 & 3.1 & 0 \\
\hline D170V & 42.4 & 9.7 & 42.3 & 9.3 & 60 \\
\hline W66L/W67L & ND & ND & 95.8 & 4.2 & 0 \\
\hline W66L & ND & ND & 96.0 & 4.0 & 0 \\
\hline W67L & 57.3 & 10.2 & 28.8 & 5.7 & na \\
\hline W100L & 30.8 & 7.3 & 55.5 & 6.5 & 68 \\
\hline W183L & 51.0 & 11.2 & 28.4 & 9.4 & 88 \\
\hline W193L & ND & ND & 96.9 & 3.1 & 0 \\
\hline W205L & 39.9 & 6.1 & 48.8 & 10.4 & 110 \\
\hline T124I & 5.8 & ND & 89.8 & 4.4 & 34 \\
\hline $\mathrm{T} 124 \mathrm{~S}$ & 46.7 & 10.2 & 28.6 & 4.5 & na \\
\hline \multicolumn{6}{|l|}{ S.cerevisiae } \\
\hline wild-type & 56.5 & 3.8 & 36.7 & 3.0 & na \\
\hline H69L & 40.1 & 2.0 & 51.6 & 6.3 & na \\
\hline E73V & 60.0 & ND & 31.7 & 8.3 & na \\
\hline E116V & 40.6 & 2.3 & 54.0 & 3.1 & na \\
\hline T119I & ND & ND & 97.9 & 2.1 & na \\
\hline
\end{tabular}

a) Sterols were those described in Table 3. b) The relative $\mathrm{Zm8} 8$,7SI activity was measured in the corresponding microsomal extracts at a $100 \mu \mathrm{M}$ concentration of (1) under the standard assay conditions. c) Percentage of total sterols ; sterols were analyzed as described in the Experimental. Data shown are means of 2 to 4 experiments ; the standard deviation was less than 5\%.d) Data shown are means of 2 experiments ; the standard deviation was less than $10 \%$; $100 \%$ activity corresponded to 17 nmole. $\mathrm{h}^{-1} \cdot \mathrm{mg} \operatorname{prot}^{-1}$ product formed .

ND: not detectable ; na : not analyzed 
B Biochemical Journal Immediate Publication. Published on 07 May 2008 as manuscript BJ20080292

Table 7. Comparative mutational analysis of plant, animal and yeast sterol 8,7-isomerases.

Corresponding mutation and (\% complementation ${ }^{\mathrm{a}}$ of the corresponding $\mathrm{w}$

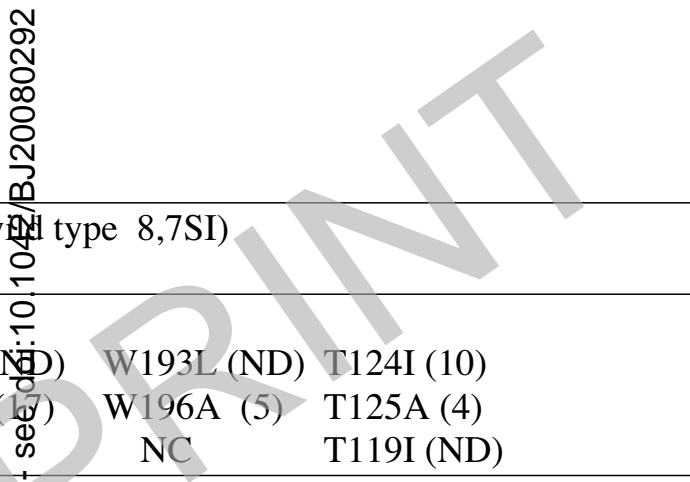

Zea mays (this work)

Homo sapiens (Ref.24)

WT (100)

H74L (ND) E78V (ND) D107V (ND) E121V (ND) W66L

WT (100)

H77A (9) E81A (5) D108A

H69L (71)

E73V (100)

$\mathrm{NC}$

(2) E122A (10)
E116V (72)

NC

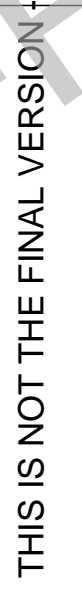

ND : not detectable

$\mathrm{NC}$ : not conserved

a) calculated as the sum of $\Delta^{5,7}$-sterols, assuming $100 \%$ complementation for the wild type enzyme.

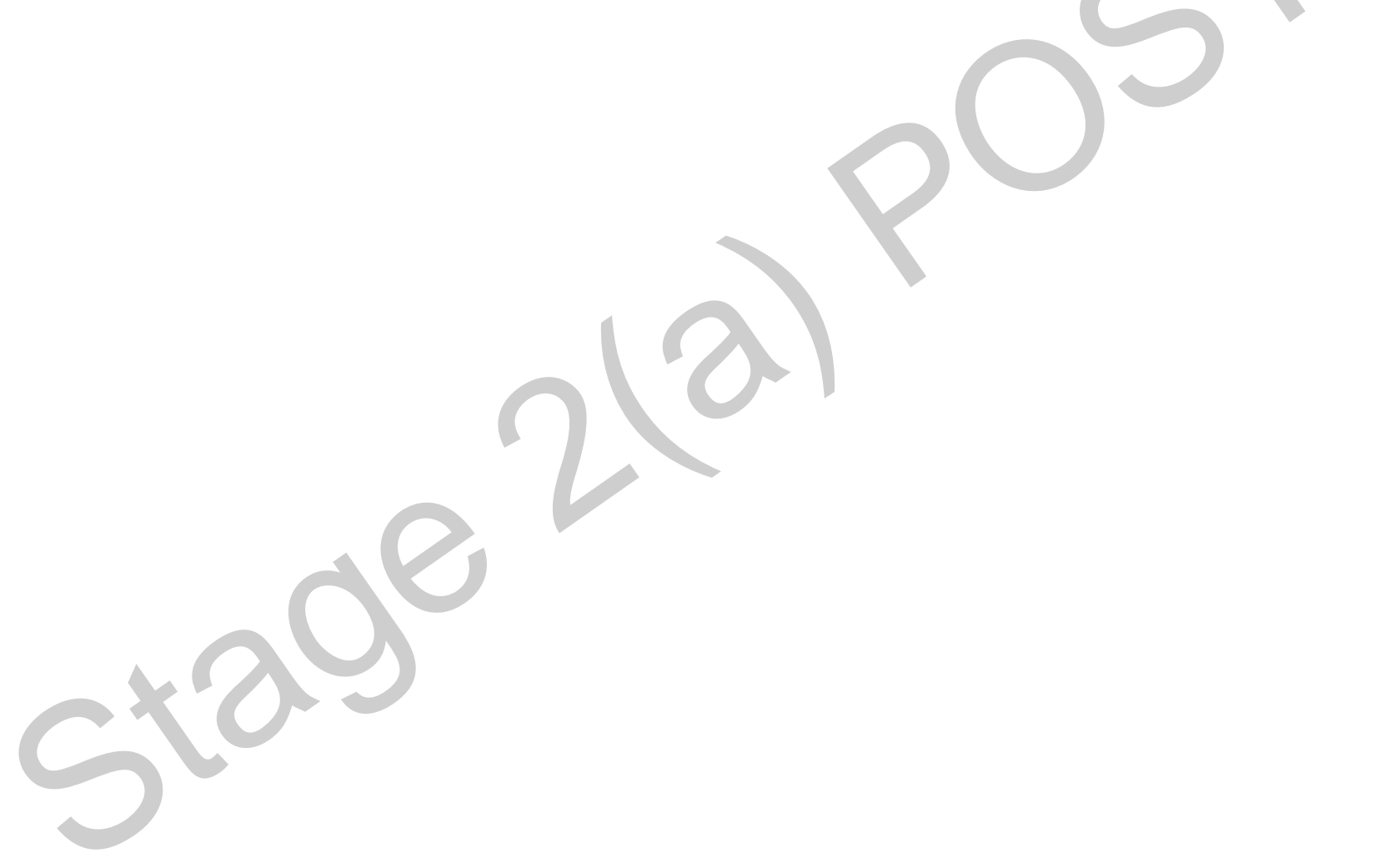

Licenced copy. Copying is not permitted, except with prior permission and as allowed by law.

(c) 2008 The Authors Journal compilation (c 2008 Biochemical Society 


\section{LEGENDS OF FIGURES.}

Figure 1 : Reaction catalyzed by the sterol 8,7-isomerase. Proposed mechanism for isomerization of $4 \alpha$-methyl-ergosta-8,24(241)-dien-3 $\beta$-ol (3) to produce $4 \alpha$-methylergosta-7,24(24 $)$-dien-3 $\beta$-ol (10) by Zm8,7SI involving C-8 $\alpha$ protonation and C-7 $\beta \mathrm{H}$ elimination. The putative carbocationic high energy intermediate is in brackets.

Figure 2 : Chemical structure of compounds considered in this study. (1) $\Delta^{8}$-Sitostenol ;

(2) Zymosterol ; (3) 4a-Methyl-fecosterol ; (4) 4,4-Dimethyl-zymosterol ; (5) 4,4-

Dimethyl-fecosterol ; (6) Obtusifoliol ; (7) Cholest-8(14)-en-3 $\beta$-ol ; (8) $\Delta^{7}$-Sitostenol ; (9)

Cholesta-7,24-dien-3 $\beta$-ol ; (10) 4 $\alpha$-Methyl-ergosta-7,24(24 $\left.{ }^{1}\right)$-dien-3 $\beta$-ol ; (11)

Tridemorph ; (12) Fenpropimorph ; (13) AY9944 ; (14) SR31747A ; (15) Trifluoperazine ; (16) Tamoxifen ; (17) N-benzyl-4 $\alpha, 10$-dimethyl-8-aza-trans-decal-3 $\beta$-ol ; (18) N-[(1,5,9)trimethyldecyl]-4 $\alpha, 10$-dimethyl-8-aza-trans-decal-3 $\beta$-ol ; (19) N-benzamido-4 $\alpha, 10$ dimethyl-8-aza-trans-decal-3 $\beta$-ol.

Figure 3 : Sequence alignment of the sterol 8,7-isomerases. Z.mays 8,7SI : AY533175; O.sativa 8,7SI : AK059848; A.thaliana 8,7SI : AF030357 ; H.sapiens 8,7SI : Z37986 ; M.musculus 8,7SI : X97755; R.norvegicus 8,7SI : AF071501; S.cerevisiae 8,7SI : M74037. Conserved residues throughout at least four sequences are shaded in gray. Z.mays 8,7SI mutated amino acids are boxed. Essential amino acid residue $(\star)$. Important amino acid residue (O). Four putative membrane-spanning domain sequences (1-4) of Zea mays $8,7 \mathrm{SI}$ are indicated.

Figure 4 : Expression of the FLAG-tagged 8,7SIs. Western blot analysis of $40 \mu \mathrm{g}$ of microsomal proteins from erg2 yeast strain overexpressing the FLAG-tagged wild type Zm8,7SI cDNA (WT) and cDNAs with the shown mutations, and of yeast transformed with vector without cDNA (Void). Proteins were resolved by SDS/PAGE and were submitted to immunoblotting with an anti-FLAG serum as described in the Experimental section. 


\section{Figure 1}

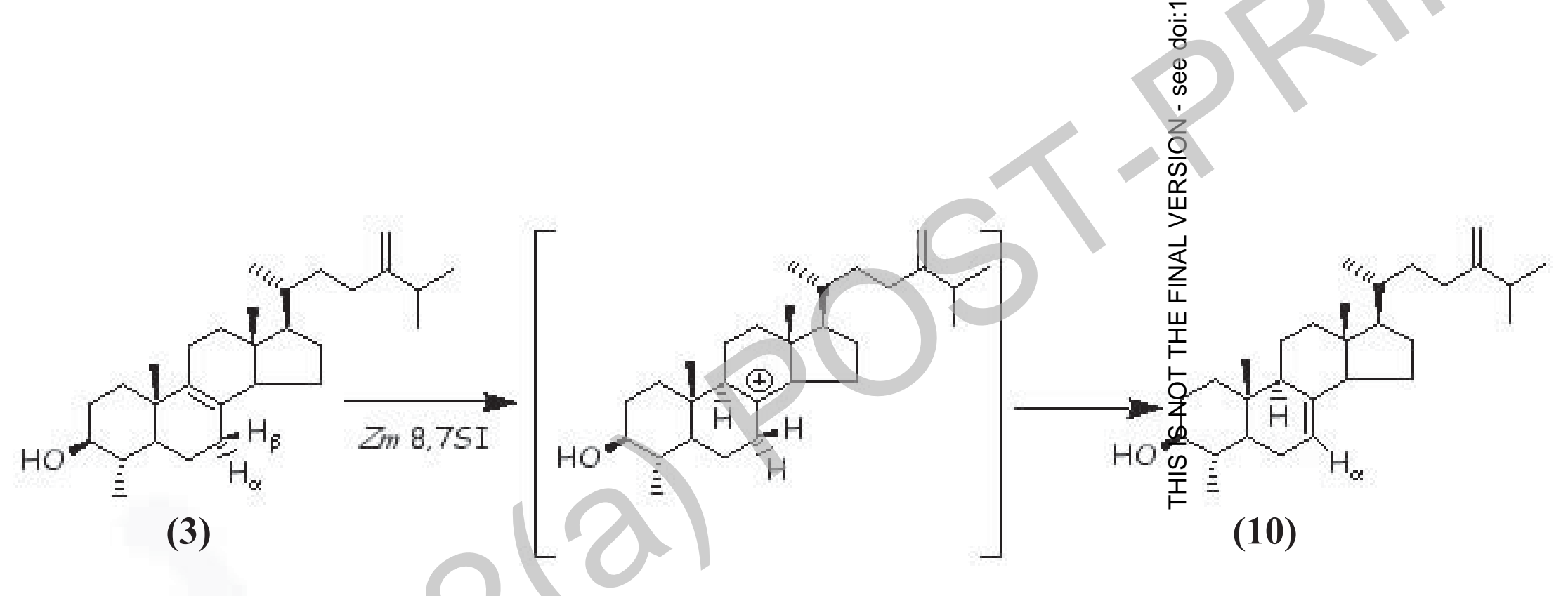




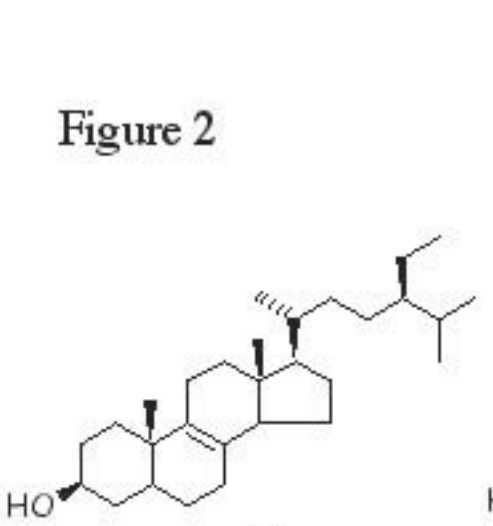

(1)<smiles>C=C(C)CCC(=C)C1CCC2C1CCC1CCC(O)CCC12C</smiles>

(6)<smiles>CC(C)CCCC(C)CCN1CC(C)O[C@H](C)C1</smiles>

(11)

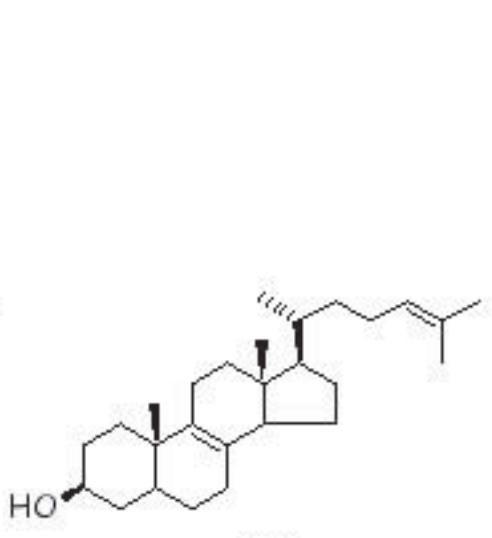

(2)

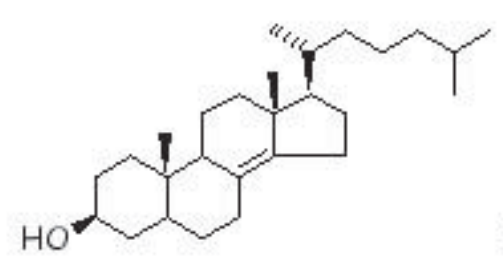

(7)

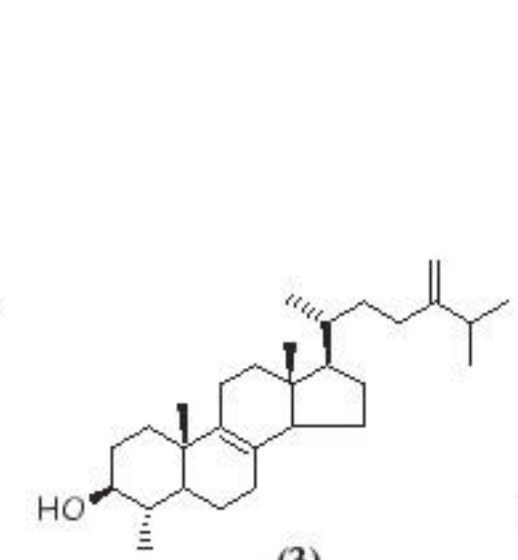

(3)

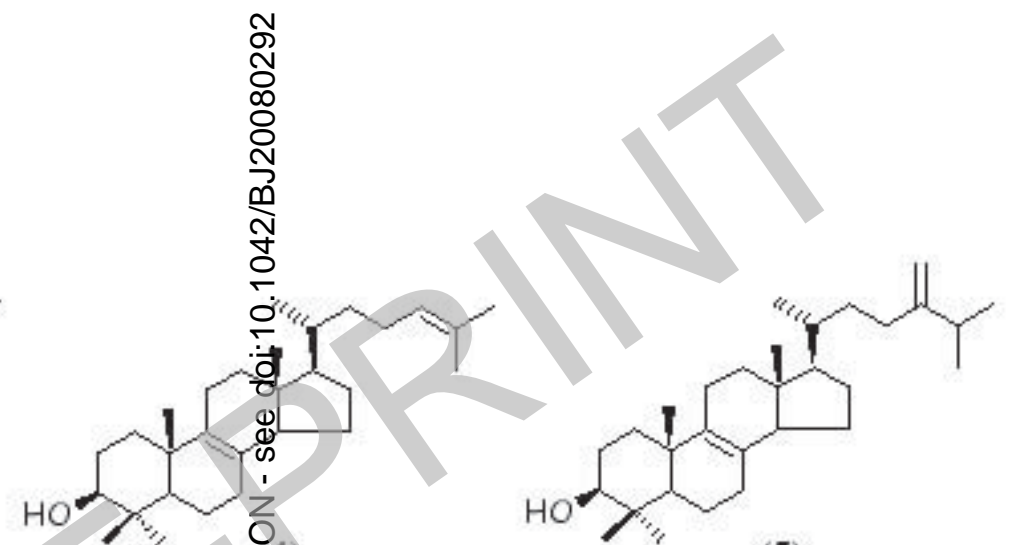

(ot)

(5)

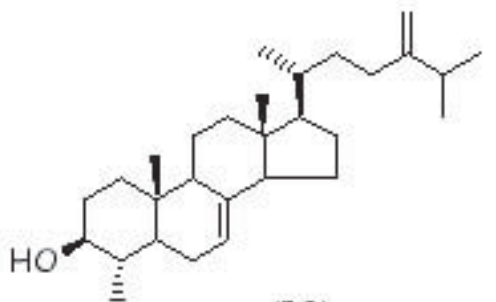

(8)

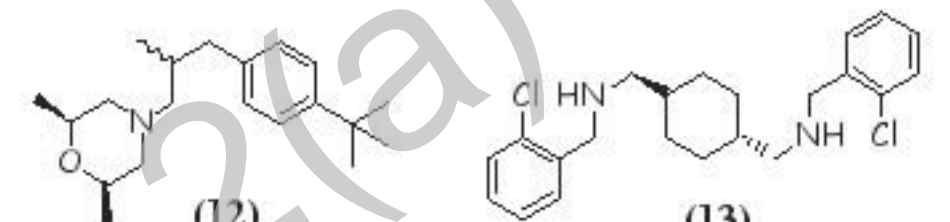

(13)

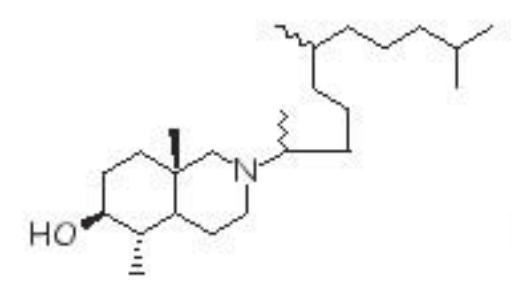

(18)

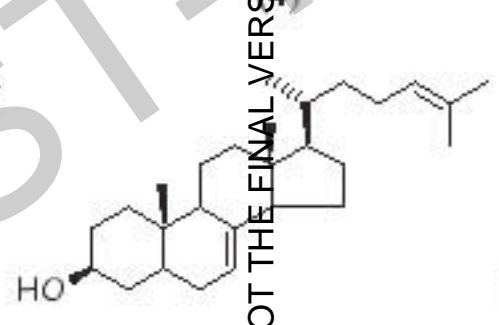

惫)

(10)

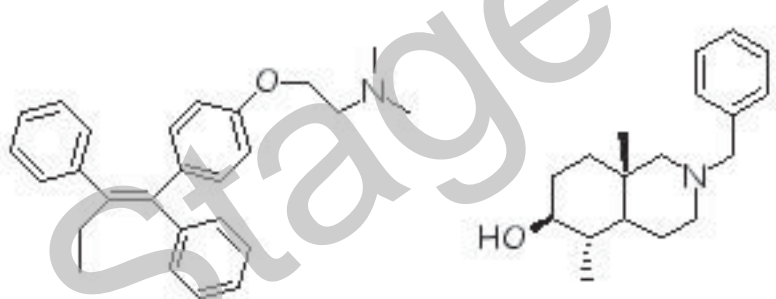

(16)

(17)<smiles>CN(C=Cc1ccc(C2CCCCC2)c(Cl)c1)C1CCCCC1</smiles>

(14)<smiles>CC1CCN(C(=O)c2ccccc2)CC1C</smiles>

(19)

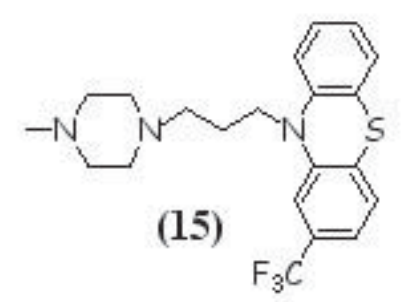




\section{Figure 3}

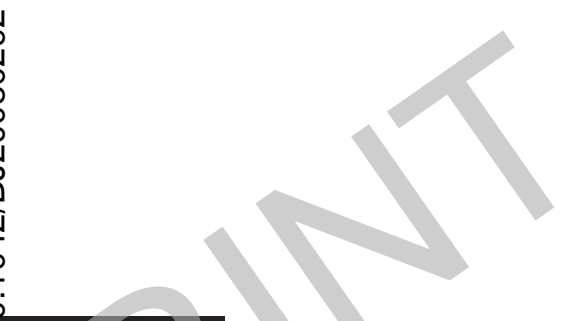

1

1. Z. mays

2. 0.sativa

4. H.sapiens

3. A.thaliana

5. M.musculus

6. R. norvegicus

7. S.cerevisiae

1. Z.mays

2. 0.sativa

4. H.sapiens

3. A.thaliana

5. M.musculus

6. R.norvegicus

7. S.cerevisiae

1. Z.mays

2. 0.sativa

4. H.sapiens

3. A.thaliana

5. M.musculus

6. R.norvegicus

7. S.cerevisiae

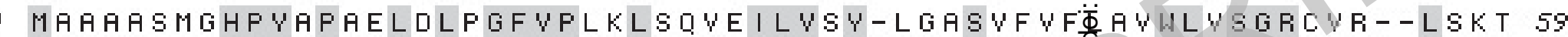
- -MGHPHPHPYAPAELHLPGFVPLQLSQAQILVPY-LATSLFLL LAVWLISGRCSRR-LSDT 58 MTTNAGPLHPYWPQHLRLDNFVPNDRPTWHILAGL-FSVTGVLV\& TTWLLSGRAAVVPLGTW 61 - - MEELAHPYVPRDLNLPGYVP I SMSMSSIVS IV-LGSSLLVUSLVWLLFGRKKA--- KL 54 MTTNTVPLHPYWPRHLKLDNFVPNDLPTSHILVGL-FS ISGGLIQ I TWLLSSRASVVPLGAG 61 MTTMMLLHPYWPRHLRLDNFVPNDLPTWHILVGL-FSFSGVLIDITWLLSSRVSVUPLGTG 61

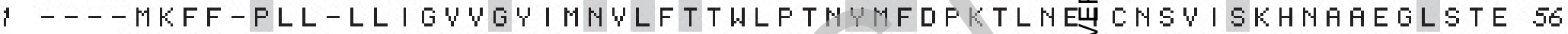

is

$2 * x$

60 DRLLMCWWAFTGLTHIMIE- - GPFVFTPDFFKKENPNFFDEV四K武VSKGDSRYVARDTATVT 119

59 DRWLMCWWAFTGLTHI I IE- - GTFVFAPNFFSNQNPSVFDEVWK世USKGDSRYVARDPATT 118

62 RRLSLCWFAVCGF I HLU |E- - GWFULYUEDLLGD-OAFLSQLWKIUAKGDSRYILGDNFTVC 120

55 DKLLMCWWTFTGLTHVI LEL- - GYFVFSPEFFKDNTSAYLAEVWKE VSKGDSRYVGRDSAVVS 114

62 RIRLLCWFAVCTF I HLV IE- - GWFSLYNGILLED-OAFLSQLWKEWSKGDSRYILSDSFVVC 120

62 RRLALCWFAVCTF I HLV IE- - GWFSFYHE ILLED-QAFLSQLWKEVSKGDSRYILSDGFIVC 120

57 DLLQDVRDALA--SHYG LEVINRYVKEEWVFNAA-GGAMGQMLISHAS-VISEYLI LFGTAVG 114
* $\quad 0$
3
4

120 VEGITRVLEGPASLLAVYAIASRKSFSHILQFAVCL-GQLYGCLVYFITAY-LDGFN--FWV 177 119 VEG ITAVLEGPASLLAVYAIASGKSYSHILQFTVCL-GQLYGCLVYFITAY-LDGFN--FWT 176 121 MET I T ACLWGPLSLWVWI AFLRQHPLRF I LQLVVSV-GQ I YGDVLYFLTEH-RDGFQHGELG 180 115 VEGITAVIVGPASLLAIYAIAKEKSYSYVLQLAISV-CQLYGCLVYFITAI-LEGDN--FAT 172 121 METVTACLWGPLSLWVVI AFLRQQPFRFVLQLVVSM-GQIYGDVLYFLTEL-HEGLQHGEIG 180 121 MESVTACLWGPLSLWVVIAFLRHQPFRFVLQLVVSV-GQIYGDVLYFLTEL-RDGFQHGELG 180 115 TEGHTGUHFA-DDVFT ILHGTQIAALPYATEAEVYTPGMTHHLKKGYAKQVSMEGGS--FAL 173

4

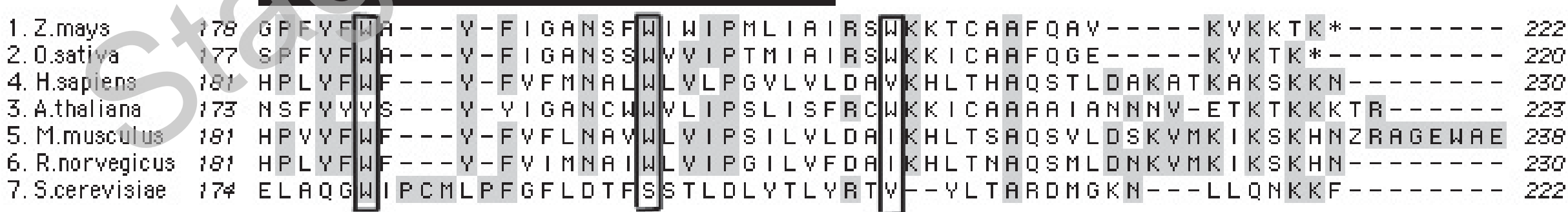
Licenced copy. Copying is not permitted, except with prior permission and as allowed by law. (c) 2008 The Authors Journal compilation (c) 2008 Biochemical Society 


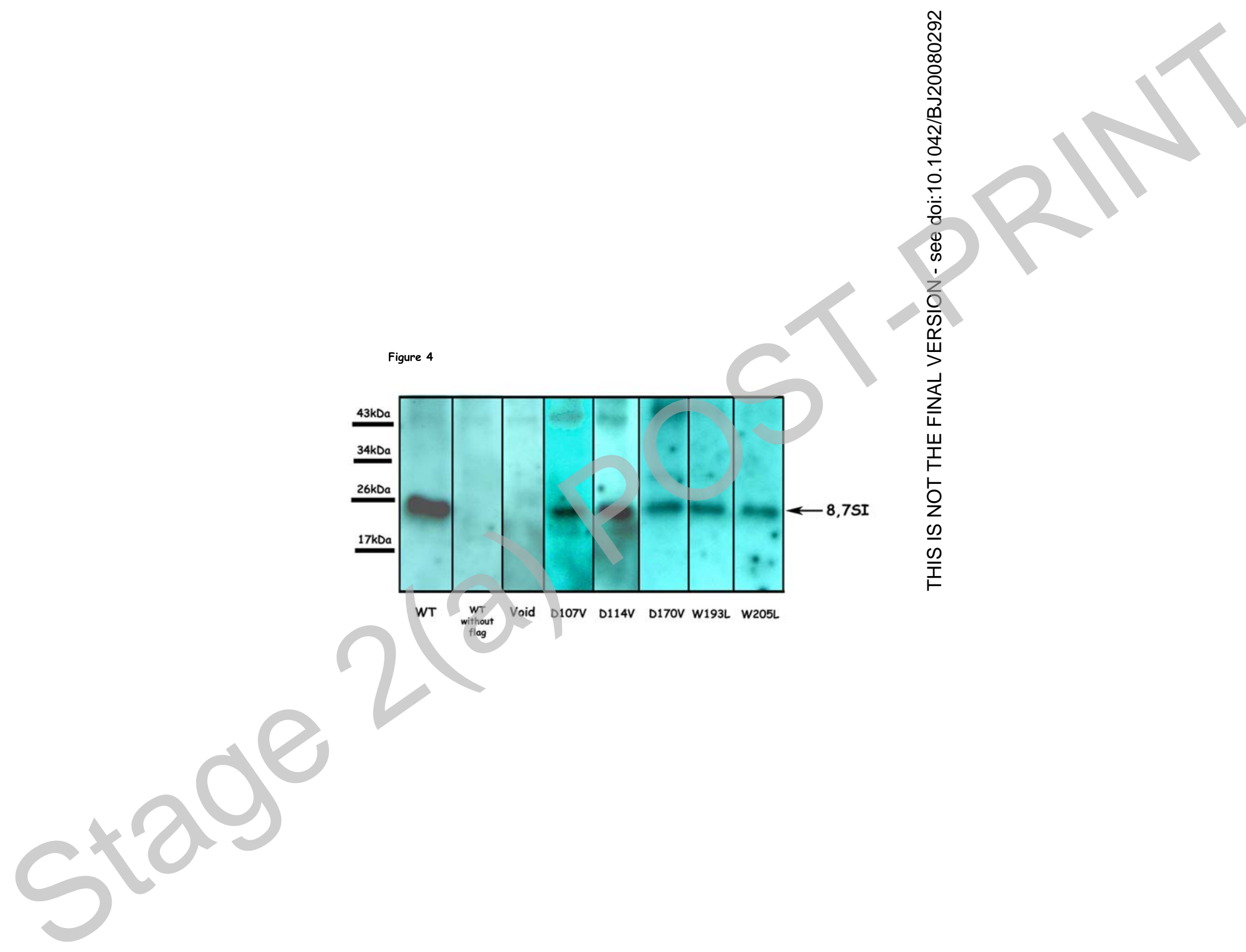

Licenced copy. Copying is not permitted, except with prior permission and as allowed by law. (c) 2008 The Authors Journal compilation (c) 2008 Biochemical Society 